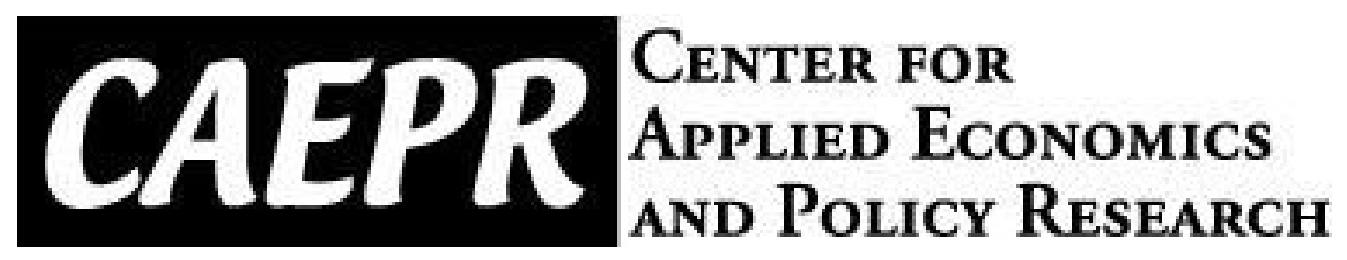

CAEPR Working Paper

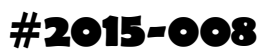

\title{
A Microfounded Design of Interconnectedness-based Macroprudential Regulation
}

\author{
Jose Fique
}

Indiana University, United States of America

April 29, 2015

This paper can be downloaded without charge from the Social Science Research Network electronic library at http://papers.ssrn.com/sol3/papers.cfm?abstract_id=2600879

The Center for Applied Economics and Policy Research resides in the Department of Economics at Indiana University Bloomington. CAEPR can be found on the Internet at:

http://www.indiana.edu/ caepr. CAEPR can be reached via email at caepr@indiana.edu or via phone at 812-855-4050.

(C)2015 by lose Fique. All rights reserved. Short sections of text, not to exceed two paragraphs, may be quoted without explicit permission provided that full credit, including $(\subset$ notice, is given to the source. 


\title{
A microfounded design of interconnectedness-based macroprudential regulation*
}

\author{
Jose Fique
}

April 29, 2015

\section{JOB MARKET PAPER}

\begin{abstract}
The failure of large, complex and interconnected banks has severe consequences to the real economy. To address the challenges posed by globally systemically important banks (G-SIBs), the Basel Committee on Banking Supervision recommended an "additional loss absorbency requirement" for these institutions. Motivated by this instrument of macroprudential regulation, which reflects concern over contagion, I develop a microfounded design of interconnectedness-based capital charges. These charges increase the costs of establishing interbank connections, which leads to a non-monotonic welfare effect. While reduced interconnectedness decreases welfare by restricting banks' ability to insure against liquidity shocks, it also increases it by reducing contagion in default states. Thus, the regulator faces a trade-off between efficiency and financial stability. I show that the trade-off implied by incentive compatible interconnectedness-based charges is steeper the stronger G-SIBs implicit support is when banks' tail risk exposure is private information. This finding underscores the importance of complementary measures, such as resolution regimes, which mitigate these frictions and consequently reinforce the efficiency and effectiveness of these capital requirements.
\end{abstract}

Keywords: Asymmetric Information, Counterparty Risk, Network Formation, Regulation.

JEL Codes: D82, D85, G01, G21, G28.

*I would like to thank, without implicating, Robert Becker, João Correia-da-Silva, Andrew Ellul, Filomena Garcia, José Jorge, Frank Page, Joana Resende, Dilyara Salakhova and Gustavo Torrens for useful comments and suggestions. I am also grateful for the financial support provided by Fundação para a Ciência and Tecnologia (Grant SFRH/BD/62309/2009) and by the Economics Department of Indiana University Bloomington. 


\section{Introduction}

The aftermath of the financial crisis brought a macroprudential layer to banking regulation. This layer consists of a set of instruments designed to mitigate systemic risk. In this paper, I develop a microfounded analysis of one these instruments. To the best of my knowledge, this is the first paper to analyze interconnectedness-based macroprudential regulation taking into account both how banks respond to the regulatory instrument and how asymmetric information and implicit government support constrain its design.

One of the macroprudential instruments is the "additional loss absorbency requirement" recommended by the Basel Committee on Banking Supervision ${ }^{1}$ for globally systemically important banks (G-SIBs). This instrument requires banks that are classified as G-SIBs to hold more capital according to their systemic importance. The classification of a bank as a G-SIB depends on, among other criteria, their interconnectedness. That is, the G-SIB status depends, to some extent, on how exposed to losses other institutions are in case of its failure. The argument for the adoption of this criterium is the following

"Financial distress at one institution can materially increase the likelihood of distress at other institutions given the network of contractual obligations in which these firms operate. A bank's systemic impact is likely to be positively related to its interconnectedness vis-à-vis other financial institutions." (BCBS; 2011, p. 7)

The adoption of this criterium reveals regulatory concern over contagion and also suggests that market discipline alone is unable to mitigate this problem. ${ }^{2}$ As seen during the crisis, in a situation where the threat of contagion materializes, the entities which were entrusted with preserving financial stability are prompted to intervene exposing taxpayers, even if only temporarily, to potentially large losses. However, when banks make their decisions, namely with respect to how interconnected they are with the rest of the financial system, they do not take into account these costs. Therefore, regulation is required to ensure that private and social incentives are aligned. Motivated by this instrument of macroprudential policy, I analyze a microfounded design of interconnectedness-based capital requirements in order to unveil the trade-off between efficiency and financial stability implied by this instrument and how market frictions constrain its design. This analysis underscores the importance of

\footnotetext{
${ }^{1}$ See BCBS (2011).

${ }^{2}$ One example that illustrates this channel of contagion is the financial distress experienced by the Reserve Primary Fund on September 16 2008. This Money Market Mutual Fund experienced substantial financial distress on account to its $\$ 785$ million exposure to commercial paper issued by Lehman Brothers. This event might have contributed to heighten the instability in financial markets, which led federal authorities to intervene shortly after. Even though this example speaks to a distress event that occurred in the shadow banking system and the regulated sector which is the focus of this paper, it illustrates the negative externalities that emerge from contagion.
} 
an integrated macroprudential policy that makes use of complementary measures, such as resolution regimes, which, by mitigating market frictions can increase the effectiveness and efficiency of interconnectedness-based capital charges. That is, I find that not only capital requirements and resolution mechanisms are complementary but they are also mutually reinforcing.

Interconnectedness-based capital charges increase the cost of establishing interbank connections, which results in a non-monotonic welfare effect. Decreased interconnectedness reduces welfare by limiting banks' ability to rely on outside sources of liquidity to face idiosyncratic liquidity shocks, which in turn reduces their ability to allocate funds to illiquid but positive net present value projects. Notwithstanding, decreased interconnectedness also limits the spread of financial distress across the interbank network, which is welfare improving. Not all banks pose an equal threat to financial stability, though. Tail risk (i.e., low-probability high-impact default events) exposure is likely to be heterogenous. As such, the efficiency - financial stability trade-off is bank dependent and is less steep the more exposed to tail risk a bank is. That is, the regulator needs to forgo comparatively less efficiency to increase financial stability when she imposes a capital requirement to a bank vulnerable to tail risk.

In frictionless markets, banks with a substantial exposure to tail risk could easily be removed by the regulator or simply be driven out of the system by market discipline, which would mitigate their negative impact on financial stability. However, it is well recognized that there are important frictions in the banking sector, namely: i) tail risk exposure is banks' private information; and ii) systemically important banks benefit from implicit government support. Consequently, the design of interconnectedness-based capital charges requires an understanding of how these market frictions affect the trade-off mentioned above.

In my model, I combine exogenous heterogeneity of banks, which leads to endogenously determined systemic risk through banks' decisions to form the interbank network, with an asymmetrically informed regulator. In the first stage, nature determines bankers' types, which determines banks' tail risk exposure through their choice of the type of assets they wish to hold in their balance sheets. In the second stage, the regulator sets a per-connection capital requirement. Finally, at the last stage, the interbank network emerges as the outcome of a network formation game where banks make their interconnectedness decisions taking their own type and capital requirements as given. After banks learn their types, they invest in a mixed portfolio of liquid and illiquid assets. These illiquid assets are heterogeneous: some are vulnerable to tail risk while others are not. Regardless of their type, they are $e x$ ante positive net present value projects but need to be refinanced before maturity in an idiosyncratic amount. To insure against this liquidity shock, banks can either invest a higher 
fraction of available funds in liquidity or establish interbank credit lines with counterparties with negatively correlated liquidity shocks, i.e., the banks endogenously form a network. Since tail risk exposure is heterogeneous and banks establish interbank connections, through which financial distress is propagated, the exogenous heterogeneity of banks leads to endogenously determined systemic risk. Moreover, this level of systemic risk is not socially optimal since banks fail to internalize the financial distress costs imposed on the regulator. Thus, to internalize this externality, before the interbank network forms, the regulator sets a perconnection capital requirement which affects banks' interconnectedness decisions.

However, the implementation of this instrument involves three challenges. First, the interbank network is an equilibrium outcome determined by banks' costs and benefits of establish interbank connections. Since capital charges introduce a cost in establishing connections, the impact on the network depends on how banks respond individually to this change in incentives. Thus, the instrument needs to induce a new welfare superior equilibrium network. Second, tail risk exposure is private information. ${ }^{3}$ In consequence, capital charges cannot be conditioned on a bank's true tail risk exposure, which requires that the design of this capital instrument to be incentive compatible. Third, the same guarantees that impair market discipline also grant systemic vulnerable banks a subsidy in default states providing an added incentive for risk taking, which in its turn incentivizes interconnectedness. By increasing its interconnectedness, banks may also increase their systemic importance and with it benefit from more substantial subsidies in default states.

Given the dual role of interbank connections, the socially optimal network must allow for an efficient liquidity allocation while ensuring that default propagation does not exceed the socially desired level. In order for this goal to be achieved, vulnerable banks should be restrained from participating in the interbank network, while sound ones should not. In frictionless markets, this goal could easily be achieved since lending conditions would reflect completely counterparty risk and/or vulnerable banks would be removed by the regulator. However, if the regulator is asymmetrically informed, then vulnerable banks cannot be preemptively excluded from the system. Thus, the regulator needs to design the requirement such that banks voluntarily select the socially optimal interconnectedness level according to

\footnotetext{
${ }^{3}$ As previously argued by Blum (2008), very large banks are complex organizations, whose assets are opaque such that even supervisors may be unable to assess perfectly ex ante the exposure to low probability high impact events. Also, banks of systemic importance may choose optimally to misreport their true tail risk exposures (see Huizinga and Laeven; 2012) since not only it makes them subject to higher capital charges but also they may anticipate regulatory forbearance. A potential explanation for this response is the regulator's desire to maintain a strong reputation as a good screener of vulnerable banks (as argued by Morrison and White; 2013) with the objective of avoiding contagion effects that would undermine the confidence in the stability of the financial system. Moreover, also as argued by Blum (2008), if there is no asymmetry of information to begin with, then capital requirements can be replaced with quantitative risk restrictions since bank behavior is perfectly anticipated.
} 
their type. ${ }^{4}$ I find that the resulting incentive compatible interconnectedness-based capital charges are characterized by a trade-off between efficiency and financial stability, which is steeper in the severity of asymmetric information and implicit government support. Not only indiscriminate higher capital requirements are needed to induce vulnerable bankers to internalize contagion costs, but also it is increasingly more difficult for the asymmetrically informed regulator to induce vulnerable banks to become less interconnected without affecting sound ones. Moreover, this difficulty is also increasing in the correlation between liquidity and credit shocks. Vulnerable banks value more interbank connections than their sound counterparts if they are more likely to be hit by a negative liquidity shock. Thus, correlation between liquidity and credit risk plays an analogous role to implicit guarantees in constraining the regulator's ability to limit the participation of vulnerable banks in the interbank market.

The model delivers some potentially important policy implications. First, an institutional framework that reduces implicit guarantees may improve financial stability through a direct and an indirect channel. Not only improved resolution regimes may reduce directly the impact of G-SIB failures, but also they can make the regulatory trade-off between financial stability and efficiency less burdensome when banks' interconnectedness decisions generate negative externalities. Second, since this trade-off is increasing in liquidity and return shock correlation, liquidity requirements such as the Net Stable Funding Ratio (NSFR) brought by Basel III can improve the effectiveness of interconnectedness-based capital requirements. Third, the main message of the paper also applies to other forms of Pigouvian taxation that were adopted via banking levies in several European countries to deal with systemic risk (see IMF 2010).

The rest of the paper is organized as follows. Section 2 presents a brief summary of the "additional loss absorbency requirement". Section 3 discusses how this paper fits in the literature. Section 4 describes the basic setup. Section 5 presents the unregulated equilibrium outcome. Section 6 analyzes the regulator's problem under complete and incomplete information. Section 7 discusses the model's policy implications. Finally, section 8 concludes.

\footnotetext{
${ }^{4}$ In the model, this corresponds to solving the game by backward induction and choosing capital charges as the solution to an unconstrained (constrained) optimization problem when the regulator has complete (incomplete) information with respect to banks' tail risk exposure. When she is asymmetrically informed, the constraints of the optimization problem correspond to the participation and incentive compatibility constraints in a standard principal-agent model. In this setting, the incentive compatibility constraints have the particular meaning of being the equilibrium network stability conditions of the pairwise stability concept (Jackson and Wolinsky; 1996).
} 


\section{G-SIBs "additional loss absorbency requirement"}

G-SIB's "additional loss absorbency requirement" follows an indicator based approach that takes into account (with equal weights) size, interconnectedness, importance to financial institution infra-structure, cross-border reach and complexity. ${ }^{5}$ G-SIBs are then allocated across four buckets as follows

Table 1: G-SIBs list as of November 2014

\begin{tabular}{|c|c|c|c|}
\hline Bucket & Institution & Bucket & Institution \\
\hline $2.5 \%$ & HSBC, JP Morgan Chase & \multirow[t]{3}{*}{$1.0 \%$} & \multirow{3}{*}{$\begin{array}{l}\text { Agricultural Bank of China, Bank of China, } \\
\text { Bank of New York Mellon, BBVA Groupe, Group BPCE, } \\
\text { Group Crédit Agricole, Industrial and Commercial Bank } \\
\text { of China Limited, ING Bank, Mizuho FG, } \\
\text { Nordea, Santander, Société Générale, } \\
\text { Standard Chartered, State Street, Sumitomo } \\
\text { Mitsui FG, UBS, Unicredit Group, Wells Fargo }\end{array}$} \\
\hline $2.0 \%$ & $\begin{array}{l}\text { Barclays, BNP Paribas, } \\
\text { Citigroup, Deutsche Bank }\end{array}$ & & \\
\hline $1.5 \%$ & $\begin{array}{l}\text { Bank of America, Credite Suisse, } \\
\text { Goldman Sachs, } \\
\text { Mitsubishi UFJ FG, Morgan Stanley, } \\
\text { Royal Bank of Scotland }\end{array}$ & & \\
\hline
\end{tabular}

source: FSB (2014)

Importantly, this allocation is not static, it is subject to periodical revisions. Thus, banks have an incentive to re-optimize their risk profile. ${ }^{6}$ When considering their interconnectedness decisions, banks internalize the costs stemming from higher capital requirements. This observation implies that capital charges have an impact on the equilibrium interbank network, which can best be analyzed using a network formation game.

\section{Related literature}

This paper is related to several strands of literature. First, it is related with the literature on financial contagion, which gained momentum after the 2007/09 crisis. Allen and Babus (2009) provide a useful review. ${ }^{7}$ This paper follows in spirit the contagion propagation mechanism of Allen and Gale (2000). Allen and Gale (2000) develop a model where an unanticipated

\footnotetext{
${ }^{5}$ The interconnectedness criteria, which is the focus of this paper, is measured by three (also equally weighted) indicators: intra-financial system assets, intra-financial system liabilities and securities outstanding. See appendix and BCBS (2011) for further details.

6“The assessment methodology provides a framework for periodically reviewing institutions' G-SIB status. That is, banks have incentives to change their risk profile and business models in ways that reduce their systemic spillover effect. (...) banks can migrate in and out of G-SIB status, and between categories of systemic importance, over time" BCBS (2011, pp. 13-14).

${ }^{7}$ Examples of more recent papers on the topic are Elliot et al. 2014, Farboodi 2014, Bluhm et al. 2013, Caballero and Simsek (2013), Georg (2013), Ladley (2013), Memmel and Sachs (2013), Zawadowski (2013), Battiston et al. (2012), Anand et al. (2012), Gai et al. (2011) and Gai and Kapadia (2010).
} 
liquidity shock triggers an initial default that propagates through the interbank network of deposits. The authors show that a more complete network exhibits a higher degree of resilience. Even though my paper follows this "domino view" of the unravelling of financial distress, I focus on the gap between private and social incentives to establish endogenously these connections and how regulation can realign those incentives to induce the network that yields the socially optimal level of systemic risk. The discussion on the optimal financial network reverts back to Leitner (2005), who shows that the danger of contagion may motivate healthy banks to rescue counterparties in distress and consequently improve financial stability. In contrast to Leitner (2005), this paper concentrates on the role of the regulator to enhance welfare and not on the private incentives of "bail-ins". It is also close to Castiglionesi and Navarro (2007) with some significant differences. While Castiglionesi and Navarro (2007) focus on a moral hazard problem, the focus of this paper is on adverse selection. Moreover, following their game theoretic approach, I model explicitly financial institutions' response to regulation and determine the optimal policy menu. More recently, Allen et al. (2012), also within a network formation game context, show that banks' private incentives to form financial connections may be misaligned with the social ones because financial institutions may not be able to select the composition of their portfolio explicitly leading to a suboptimal network. The market failure in my paper differs from theirs since in my setting banks fail to take into account the negative externality that their decisions impose on the deposit insurer/regulator. Bluhm et al. 2013 also study the effects of regulatory measures, such as systemic risk charges, on the endogenous formation of the financial network. The authors analyze the effect of macroprudential policy on the endogenous structure of the dynamic network within an agent-based model. The main difference is that in my paper the focus is on the design of a policy menu that induces banks to form the socially efficient network in the presence of market frictions. My paper follows a mechanism design approach to network formation related with Mutuswami and Winter (2002). This approach provides a unique perspective on the incentives that banks have to establish connections, which allows to analyze the importance of complementary instruments for the effectiveness of interconnectednessbased capital requirements. Second, the paper is also related with the network based systemic risk contribution literature (e.g., Tarashev et al. 2009, Gai et al. 2011, Staum 2012, Drehmann and Tarashev 2013 and Bluhm and Krahnen 2014). However, unlike these papers based on the Shapley (1950) value, the topology of the network is not assumed to remain fixed. This is particularly important when banks have different incentives to become interconnected and the regulator faces an informational disadvantage. Finally, the paper is also close to the literature on the effects of capital requirements under asymmetric information (e.g., VanHoose 2007 and references therein, Blum 2008, Vollmer and Wiese 2013) and incentive based regulation 
(e.g., Campbell et al. 1992, Chan et al. 1992, Giammarino et al. 1993).

\section{The model}

Consider an economy with three regions (indexed by $i=1,2,3$ ), each with a representative bank $\left(b_{i}\right)$ and a continuum of depositors of measure one. Time is discrete and there are 4 periods $(t=-1,0,1,2)$. Depositors are only endowed with one unit of the numeraire good at $t=0$ and nothing at subsequent dates. Depositors are fully insured. Banks are owned and managed by a banker. Bankers use their own capital $(k)$, raised in capital markets, and their depositors endowments to invest in a mixed portfolio of liquid $(y)$ and ex ante positive net present value illiquid $(x)$ assets. In return, depositors receive a fixed return $\left(r_{d}\right)$ at $t=2$. Depositors are either repaid by their banker or, in case he is not able to, by the deposit insurer.

The liquid asset is the standard storage technology available in every period. There are two types of illiquid assets: sound and vulnerable. Vulnerable assets are exposed to tail risk, that is, with a small probability they return 0 at $t=2$. The choice between sound and vulnerable assets depends on the ability of the banker, which is drawn by nature at $t=-1$. Regardless of their type, illiquid assets require additional cash injections at $t=1$ in order to mature at $t=2$. To insure against this idiosyncratic liquidity shock, bankers can either hold more liquidity in their balance sheets or establish interbank credit lines. The collection of these credit lines is the interbank network. The timeline of the model is displayed in Figure 1.

Figure 1: Timeline

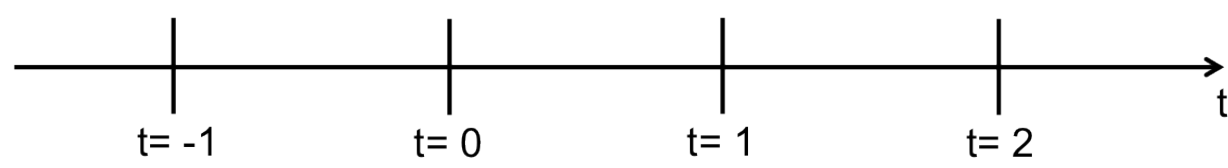

- Nature determines bankers' types
- Consumers deposit their endowments

- Bankers choose their asset allocation

- Interbank network forms
- Assets mature

- Depositors are repaid (either by their banks or by deposit insurer) 


\subsection{Return shocks}

The illiquid asset may be subject to a return shock at maturity, which occurs at $t=2$, if it is vulnerable to tail risk. An asset is vulnerable if it yields $R$ at maturity with probability $\beta<1$ and nothing otherwise per unit of the numeraire invested at $t=0 .{ }^{8}$ Conversely, an asset is sound if it returns $R>1$ at maturity per unit of the numeraire invested at $t=0$ with probability one. Table 2 displays assets' cash-flows.

Table 2: Assets' cash-flows

\begin{tabular}{|c|c|c|c|c|}
\hline \multicolumn{2}{|l|}{ Asset } & $t=0$ & $t=1$ & $t=2$ \\
\hline \multirow[b]{2}{*}{ illiquid asset $(x)$} & sound & -1 & 0 & $R$ \\
\hline & vulnerable & -1 & 0 & $\begin{array}{ll}R & \text { with prob. } \beta \\
0 & \text { otherwise }\end{array}$ \\
\hline \multirow{2}{*}{\multicolumn{2}{|c|}{ liquidity $(y)$}} & -1 & 1 & - \\
\hline & & - & -1 & 1 \\
\hline
\end{tabular}

Even though illiquid asset's quality is heterogeneous, without additional information, bankers are unable to distinguish between vulnerable and sound assets at $t=0$. Moreover, I assume that the liquidation value of this asset before maturity is zero. ${ }^{9}$ Notwithstanding, bankers can learn their type, or exposure to tail risk, at a cost. ${ }^{10}$ Let $C\left(\theta^{i}\right)$ denote the

\footnotetext{
${ }^{8}$ One can think of sound and vulnerable assets as AAA-rated corporate bonds and collateralized debt obligations, respectively. During normal times (i.e., pre-crisis) these assets received the same rating. However, after the crisis, their returns were significantly different. Griffin and Tang (2012) show that a sample of corporate bonds and collateralized debt obligations (CDO), which received the AAA rating before the crisis, exhibited significant heterogeneity in their ratings after the crisis. While the majority of corporate bonds retained the AAA rating, roughly half of the sample CDO's were either downgraded to non-investment grade or defaulted.

${ }^{9}$ This assumption can be motivated by considering the loss in value brought by asymmetry of information with respect to asset quality.

${ }^{10}$ For example, instead of relying only on credit ratings, banks can invest in internal risk models that provide a better assessment of asset's cash-flows. This distinction in Morrison and White (2005, 2011, 2013) is motivated by differences in access to monitoring technologies. Also, note that assuming that the probability of success is equal to one is without real loss of generality. All results follow from the difference between success probabilities and not from their levels. This assumption can be further motivated by the contrasting resilience that financial institutions displayed during the 2007 crisis. As Senior Supervisors Group (2008, p. 3) puts it, "firms that faced more significant challenges in late 2007 generally had not established or made rigorous use of internal processes to challenge valuations. They continued to price the super-senior tranches of CDOs at or close to par despite observable deterioration in the performance of the underlying RMBS collateral and declining market liquidity. Management did not exercise sufficient discipline over the valuation process: those firms generally lacked relevant internal valuation models and sometimes relied too passively on external views of credit risk from rating agencies and pricing services to determine values for their exposures. Given that the firms surveyed for this review are major participants in credit markets, some firms' dependence on external assessments such as rating agencies' views of the risk inherent in these securities contrasts with more sophisticated internal processes they already maintain to assess credit risk in
} 
cost to banker $i$ of selecting sound assets from a pool of apparently identical assets. If the banker chooses not to select a sound asset, he is left with a vulnerable asset but does not incur in $C\left(\theta^{i}\right)$. Moreover, I assume that $C\left(\theta_{L}\right)>C\left(\theta_{H}\right)$. That is, high ability bankers have a comparative advantage in selecting sound assets. Following Giammarino et al. (1993), I assume bankers have resources $B$ that can either be used for sound asset selection or consumed without social value.

I assume that banks know their own type, but outsiders only observe the ex ante distribution of $\Theta$. As a baseline, I assume $b_{1}$ and $b_{3}$ are managed by low ability and $b_{2}$ by a high ability banker, respectively. The assignment of $b_{2}$ as the sound bank is without loss of generality, only the distribution of the types is relevant. The particular choice of the distribution of $\Theta=\left\{\theta^{1}, \theta^{2}, \theta^{3}\right\}$ is discussed in the conclusion.

\subsection{Liquidity shocks}

Before these illiquid assets mature, however, each banker faces the need to refinance the illiquid share of his portfolio at $t=1$. Without this injection of cash illiquid assets fail to mature, that is, they return 0 at $t=2$.

Let $\gamma^{i}(\omega) \in\left\{\gamma_{L}, \bar{\gamma}, \gamma_{H}\right\}$ denote the amount of liquidity the banker $i$ needs to refinance his illiquid asset at $t=1$ in state $\omega$, with $\gamma_{H}>\gamma_{L}$ and $\bar{\gamma}=\left(\gamma_{H}+\gamma_{L}\right) / 2$. An example of this shock is the additional cash injection required by a non financial corporation to carry out a project to its maturity. Also, I assume these are "pure" liquidity shocks. If banker $i$ is required to inject an above average cash amount at $t=1$, the above average cash injection is returned at $t=2$. That is, if at $t=1$, the banker faces a shock equal to $\gamma_{L}$, then the asset at maturity returns $x R-\left(\bar{\gamma}-\gamma_{L}\right)$ in success states. Alternatively, one can think of these shocks as stochastic depositor withdrawals when banks choose to refinance their long-term assets with short-term debt. Table 3 describes the distribution over the set of liquidity shocks $\Omega$ (with typical element $\omega$ ).

other business lines. Furthermore, when considering how the value of their exposures would behave in the future, they often continued to rely on estimates of asset correlation that reflected more favorable market conditions." 
Table 3: Regional Liquidity Shocks

\begin{tabular}{|c|c|c|c|c|}
\hline$\omega$ & Prob. & $b_{1}$ & $b_{2}$ & $b_{3}$ \\
\hline \hline$\omega_{1}$ & $\phi_{1}$ & $\gamma_{L}$ & $\bar{\gamma}$ & $\gamma_{H}$ \\
\hline$\omega_{2}$ & $\phi_{2}$ & $\gamma_{L}$ & $\gamma_{H}$ & $\bar{\gamma}$ \\
\hline$\omega_{3}$ & $\phi_{3}$ & $\bar{\gamma}$ & $\gamma_{L}$ & $\gamma_{H}$ \\
\hline$\omega_{4}$ & $\phi_{4}$ & $\bar{\gamma}$ & $\gamma_{H}$ & $\gamma_{L}$ \\
\hline$\omega_{5}$ & $\phi_{5}$ & $\gamma_{H}$ & $\gamma_{L}$ & $\bar{\gamma}$ \\
\hline$\omega_{6}$ & $\phi_{6}$ & $\gamma_{H}$ & $\bar{\gamma}$ & $\gamma_{L}$ \\
\hline
\end{tabular}

I assume that idiosyncratic liquidity shocks are independent, uniformly distributed and are independent of return shocks. That is, $\phi_{1}=\phi_{2}=\ldots=\phi_{6}=\frac{1}{6}$. In 7, this assumption is replaced with a more realistic where liquidity and credit shocks are allowed to be correlated.

Combining return and liquidity shocks, the state space is defined as the Cartesian product of credit and liquidity shocks $(\Omega \times \tilde{R})$ with typical element $(\omega, \tilde{r})$, where $\omega$ and $\tilde{\boldsymbol{r}}$ are the sets of realized asset returns and liquidity shocks, respectively.

\subsection{Interbank credit lines}

To face these liquidity shocks banks can invest in the storage technology or establish ex ante bilateral credit lines. ${ }^{11}$ Let $\mathcal{B}$ be the set of borrowers and $\mathcal{L}$ the set of lenders. These credit lines are directed such that a bank can be a borrower $\left(b_{i} \in \mathcal{B}\right)$ without being simultaneously a lender $\left(b_{j} \in \mathcal{L}\right)$. For example, in states $\left(\omega_{6}, \tilde{\boldsymbol{r}}\right)$, through a credit line, $b_{1}$ can obtain liquidity from $b_{3}$. This example credit line is represented as $\left\{\left(b_{3}, b_{1}\right)\right\}$ or graphically $b_{3} \rightarrow b_{1}$.

The collection of all these credit lines constitutes the interbank network. In network theory terminology, the interbank market is a directed homogeneous network $(G)$.

Definition 1. (Interbank Network) An interbank network $G$ is a subset of $\mathcal{G}:=(\mathcal{L} \times \mathcal{B})$ with typical element $\left(b_{i}, b_{j}\right)$ such that for all potential lenders $b_{i} \in \mathcal{L}$, the section of $G$ at $b_{i}$ given by

$$
G\left(b_{i}\right):=\left\{b_{j} \in \mathcal{B}:\left(b_{i}, b_{j}\right) \in G\right\}
$$

is non empty. Moreover, let $z_{i}^{j}(G, \omega)$ denote the amount of liquidity available to bank $j$ through the credit line with $i$ in state $(\omega, \tilde{\boldsymbol{r}})$, with $z_{i}^{i}(G, \omega)=0$ by convention.

Even though these interbank credit lines allow banks to insure against liquidity shocks, the existence of vulnerable banks also exposes lenders to the potential of a default by contagion.

\footnotetext{
${ }^{11}$ see Cocco et al.; 2009 for empirical evidence that supports this claim.
} 
A default by contagion occurs whenever the lender is unable to fulfill its obligations with its own depositors due to the failure of a borrower. Since the model assumes pure liquidity shocks, the liquidation value of the lender's portfolio must be sufficient to repay depositors in order to remain solvent. Given that bank $i$ can only be a lender if the liquidity shock, $\gamma^{i}$, at the interim date is less than $y$, the residual value at maturity $(1-y) R-\left(\bar{\gamma}-\gamma_{L}\right)$ needs to be greater than $r_{d}$ to ensure solvency. ${ }^{12}$

In the absence of market frictions, the interest rate on these credit lines would reflect the borrower's true exposure to tail risk. Let $\beta^{\star} \geq \beta$ denote the perceived probability of success of the borrower bank. This probability can differ from the true probability of success for two reasons. First, the expectation of government support in states where tail risk materializes dampens market discipline. That is, anticipating that the borrower will be bailed out leads to a higher perceived probability of success or alternatively reduces the interest rate required by the lender. Second, since tail risk exposure is private information, the interbank interest rate captures the average counterparty risk instead of the borrower's individual counterparty risk implied by his exposure to tail risk. Thus, assuming, for simplicity, that the borrower holds all the bargaining power, ${ }^{13}$ the expected interbank interest rate is given by

$$
\begin{aligned}
r_{I B}^{i}\left(G, y, k, \beta^{\star}, R, r_{d}\right)= & \sum_{j \in G_{i}^{-}} \tilde{\phi}^{j} \frac{1-\beta^{\star}}{\beta^{\star}}\left[\left(1+k^{j}-y^{j}\right) R-r_{d}-\delta k^{j}\right] \times 1_{\text {contagion }_{j}+}+ \\
& \sum_{j \in G_{i}^{-}} \tilde{\phi}^{j} \frac{1-\beta^{\star}}{\beta^{\star}}\left(\bar{\gamma}-\gamma_{L}\right) \times\left(1-\mathbf{1}_{\text {contagion }_{j}}\right),
\end{aligned}
$$

where $G_{i}^{-}$is the set of all banks that are potential lenders to bank $i, \delta$ is the opportunity cost of capital, $\tilde{\phi}^{j}=\sum_{\omega \in \Omega}\left[\mathbf{1}_{\mid y_{i}+z_{i}^{j}(G, \omega) \geq \gamma^{i}(\omega)}-\mathbf{1}_{\mid y_{i} \geq \gamma^{i}(\omega)}\right] / 6$ is the probability of occurrence of the state where $i$ can only survive the liquidity shock by drawing on the credit line with $j$ and $1_{\text {contagion }_{j}}$ is an indicator function that takes the value 1 if $j$ is not able to repay his depositors as a consequence of the loss sustained on the interbank credit line with the default of $i . \mathbf{y}$ and $\mathbf{k}$ are the liquidity and capital choices of all banks in the system.

Essentially, equation (1) can be decomposed in two terms. The first, is the interest rate $j$ requires in order to lend to $i$ when $j$ defaults in consequence of the default of $i$ given the

\footnotetext{
${ }^{12}$ These credit lines can be substantial in practice. Upper (2011) reports that interbank loans can amount to several multiples of banks' equity in some European countries prior to the crisis. Alternatively, these credit lines can be thought of as over-the-counter (OTC) contracts in general that expose banks to the failure of their counterparties.

${ }^{13}$ Any other interest rate within the banks' reservation price range, for example resulting from Nash bargaining, would not change qualitatively the results. For an example of how Nash bargaining can be used in a network context see Braun and Gautschi (2006).
} 
size of the interbank credit lines. This interest rate makes $j$ indifferent between lending and not lending to $i$. That is, it is obtained by equating the expected payoff of $j$ when $i$ does not default, $\beta^{\star}\left(r_{I B}+\left(1+k^{j}-y^{j}\right) R-r_{d}-\delta k^{j}\right)$, with the payoff of $j$ when he does not lend, $\left(1+k^{j}-y^{j}\right) R-r_{d}-\delta k^{j} .{ }^{14}$ The derivation of the first term is in appendix. The second, is the interest rate $j$ requires in order to lend to $i$ when $j$ does not default in consequence of the default of $i$ given the size of the interbank credit lines. If the loss $j$ sustains with the default of $i$ is not sufficient to compromise his ability to repay his depositors, then $j$ only loses the amount loaned to $i$. As in the previous term, the interest rate is the one that makes $j$ indifferent between lending and not lending.

\subsection{Intermediation}

In addition to bilateral liquidity insurance, the interbank network also allows for intermediation. Intermediation extends the amount of liquidity, $z_{i}(G, \omega)$, available to bank $i$ through the network $G$ in states $(\tilde{\boldsymbol{r}}, \omega)$ beyond what direct lenders can provide through bilateral credit lines. For example, even in the absence of a credit line between $b_{1}$ and $b_{3}, b_{1}$ can still obtain the needed liquidity provided that both $b_{1}$ and $b_{3}$ have opposite credit lines with $b_{2}$. In describing how intermediation operates in this model it is useful to define a path. Formally, a sequence of credit lines $\left\{\left(b_{i}, b_{j}\right)_{l}\right\}_{l=1}^{2}$ forms a path between $b_{i}$ and $b_{m}$ if

$$
\exists\left\{\left(b_{i}, b_{j}\right)_{1},\left(b_{j}, b_{m}\right)_{2}\right\} \subseteq G
$$

with $b_{i} \neq b_{j} \neq b_{m}$.

In states where banks cannot obtain liquidity directly from their counterparties, survival to the liquidity shock can be achieved if a bank with excess liquidity can provide it, through an intermediary. For this to be possible the bank with the liquidity shortage and the one with excess liquidity must be connected through a path of length 2 . In order for counterparty risk involved in intermediation to be fully accounted for, I assume the interbank network is common knowledge. ${ }^{15}$

When a banker intermediates a transfer of funds, he has to borrow the needed liquidity from the surplus bank to then lend it to the deficit bank. Thus, under assumption the interbank network is common knowledge, the expected fees owed to the intermediary reflect not only the borrower's expected risk, but also the expected counterparty risk of the intermedi-

\footnotetext{
${ }^{14}$ Note that the choice of the type of illiquid asset by the lender does not play a role in the determination of $r_{I B}$. This is the case because return shocks are assumed to be independent across banks, such that both the expected payoffs of lending and not lending are adjusted equally by the lender's own probability of default.

${ }^{15}$ This assumption is not strictly necessary. Intermediation fees can be derived based on only a limited knowledge of the network. See Caballero and Simsek; 2013 for an exposition on how Knightian uncertainty can be accounted for in the context of a financial network).
} 
ary. For simplicity, I keep the assumption that the borrower holds all the bargaining power such that both the lender and the intermediary are only compensated for the counterparty risk involved in providing liquidity to the borrower. Thus, the fees the borrower pays in addition to the interest rate on the credit line are given as follows

$$
\begin{aligned}
& \epsilon_{i}\left(G, y, k, \beta^{\star}, R, r_{d}\right)= \\
& \left\{\begin{array}{lc}
\frac{1-\beta^{\star}}{\left(\beta^{\star}\right)^{2}} \sum_{m \in \tilde{\mathcal{M}}} \tilde{\phi}^{m}\left[\left(1+k^{m}-y^{m}\right) R-r_{d}-\delta k^{m}\right] \times \mathbf{1}_{\mid \text {contagion }_{m}}+ & \text { if } i \text { borrows via } \\
\frac{1-\beta^{\star}}{\beta^{\star}} \sum_{j \in \tilde{\mathcal{I}}} \tilde{\phi}^{j}\left(\bar{\gamma}-\gamma_{L}\right) \times\left(1-\mathbf{1}_{\text {contagion }_{j}}\right) & \text { intermediary } j \\
0 & \text { if } i \text { borrows from }
\end{array}\right.
\end{aligned}
$$

where $m \in \tilde{\mathcal{M}} \backslash\left\{G_{i}^{-}\right\}$is any bank in the set of banks with a liquidity surplus which are not potential lenders of $i$ and $j \in \tilde{\mathcal{I}}$ is any intermediary on the set of banks positioned in the path between $i$ and $m .^{16}$

\subsection{Banker's problem}

Banker $i^{\prime}$ s expected profits, at $t=0$, are given by

$$
\mathbb{E}\left[\pi_{i}(G, k, y, \theta, s)\right]=\left\{\begin{array}{cl}
{\left[\left(1+k^{i}-y^{i}\right) R-r_{d}-r_{I B}^{i}\right] \phi_{i}(G)-} & \text { if } s=\text { sound } \\
\epsilon_{i}-\delta k^{i}+B-C\left(\theta^{i}\right) & \\
{\left[\left(1+k^{i}-y^{i}\right) R-r_{d}-r_{I B}^{i}\right] \beta \phi_{i}(G)-} & \text { if } s=\text { vulnerable } \\
\epsilon_{i} \beta-\delta k^{i}+B+(1-\beta) \nu\left|G_{i}^{-}\right| &
\end{array}\right.
$$

where $\phi_{i}(G)=\sum_{l \in\left\{b_{1}, b_{2}, b_{3}\right\}} \mathbf{1}_{\mid y_{i}+z_{i}^{l}(G, \omega) \geq \gamma^{i}(\omega)} / 6$ is the network dependent probability of survival to the liquidity shock of bank $i$ (increasing in the potential borrower's connections), $\nu$ is the per connection expected bail out subsidy, $\left|G_{i}^{-}\right|$is $i^{\prime}$ s number of incoming credit lines and $\epsilon_{i}\left(G, \mathbf{y}, \mathbf{k}, \beta^{\star}, R, r_{d}\right)$, are the net intermediation fees.

If the banker chooses to invest in the illiquid sound asset, the expected profit has four components. $\left(1+k^{i}-y^{i}\right)$ is the return on the amount invested in the illiquid asset ${ }^{17}$ net of

\footnotetext{
${ }^{16}$ See the derivation of the interbank interest rate for the details on this function.

${ }^{17}$ Where the budget constraint holds with equality.
} 
the interest rate on deposits and credit lines. However, this return is only realized if the bank survives the liquidity shock at the interim date, which occurs with probability $\phi(G) . \epsilon_{i}$ are the net intermediation fees. $\delta k^{i}$ is the opportunity cost of capital. Finally, $B-C\left(\theta^{i}\right)$ is the amount of resources available for the banker's consumption after incurring the cost of sound asset selection.

If the banker chooses to invest in the vulnerable illiquid asset, expected profit changes. He no longer faces $C\left(\theta^{i}\right)$, but in addition to the liquidity shock he also faces the return shock. That is, the illiquid asset matures only with probability $\beta$. In addition, he receives a bail out subsidy which is increasing in the bank's connectivity. ${ }^{18}$

Then, the optimization problem solved by bankers can be described as

$$
\max _{k, y, G_{i}} \mathbb{E}\left[\pi_{i}\left(G, k^{i}, y^{i}, \theta^{i}, s\right)\right]
$$

s.t.

$$
\begin{gathered}
1+k^{i} \geq y^{i} \geq 0 \\
k^{i} \geq 0
\end{gathered}
$$

where equations (4) and (5) are the feasibility and capital non-negativity constraints, respectively. Note that in addition to the balance sheet allocation, bankers also make network proposals that affect the equilibrium interbank network $G$.

\footnotetext{
${ }^{18}$ This subsidy is the result of a time-inconsistent bank closure policy (see Freixas; 1999 and Acharya and Yorulmazer; 2007 for a formal treatment), which is formalized in section 6 . That is, ex ante the regulator would like to commit to close problematic banks, but ex post she finds optimal to bail them out. This is the case because ex post the financial distress costs avoided by a bail out outweigh its costs. These subsidies are assumed to be exogenous to capture the constraints that the institutional framework impose on the choice of the regulator between a bail out and a bank liquidation. Given the choice of interconnectedness as a criterium to identify G-SIBs, it is plausible to assume that financial distress costs are increasing in it. Consequently, the time-inconsistency problem of the closure policy may be worsened with interconnectedness leading to a bail out subsidy also increasing in interconnectedness. As Bayazitova and Shivdasani (2012) show, interconnectedness was a determinant when approving TARP's Capital Purchase Program (CPP) applications. Bayazitova and Shivdasani find that the ratio of the notional value of the bank's derivates to total assets and the wholesale debt ratio leads to an increase in the probability of a CPP application to be approved by the U.S. Treasury. Equation (2) illustrates two channels through which implicit guarantees affect expected profits. The first, the funding (or supply side) channel, is reflected in the interest rate on wholesale credit lines. Since creditors expect a bail out in default states, they require a lower interbank interest rate. The second, the insurance (or demand side) channel, is reflected on the subsidy that vulnerable banks benefit in default states.
} 


\subsection{Equilibrium}

This equilibrium network is defined using the pairwise stability equilibrium concept of Jackson and Wolinsky (1996).

Definition 2. (Pairwise-stable network) An interbank network $G \in \mathcal{G}$ is pairwise-stable (PWS) if

(i) for all $(i, j) \in G\left(i, j \in\left\{b_{1}, b_{2}, b_{3}\right\}\right.$ and $\left.i \neq j\right)$ we have

$$
\mathbb{E}\left[\pi_{k}(G, \cdot)\right] \geq \mathbb{E}\left[\pi_{k}(G \backslash(i, j), \cdot)\right] \text {, with } k=i, j
$$

(ii) for all $(i, j) \notin G\left(i, j \in\left\{b_{1}, b_{2}, b_{3}\right\}\right.$ and $\left.i \neq j\right)$ we have

$$
\mathbb{E}\left[\pi_{j}(G, \cdot)\right]>\mathbb{E}\left[\pi_{j}(G \cup\{(i, j)\}, \cdot)\right] \Rightarrow \mathbb{E}\left[\pi_{i}(G, \cdot)\right]<\mathbb{E}\left[\pi_{i}(G \cup\{(i, j)\}, \cdot)\right]
$$

Statement (i) requires that it is not possible, in equilibrium, for any of the two banks to have a profitable deviation by severing one connection. That is, the additional credit line established between $i$ and $j$ makes both banks at least as well off as without the liquidity insurance opportunity. Statement (ii), on its turn, requires that if one of the parties is strictly better off with the deviation, then it must be that the other party is strictly worse off. Thus, adding a credit line requires that both banks agree, but severing a connection can be done unilaterally.

Definition 3. (Equilibrium) An equilibrium in the banking system is defined as a set of portfolio allocations, capital holdings and a set of PWS interbank networks that solves problem (3) subject to constraints (4) and (5) for each banker $i \in\left\{b_{1}, b_{2}, b_{3}\right\}$.

\subsection{Assumptions}

To preserve the economic interest of the model such that contagion is a regulatory concern, as suggested by the policy under analysis, I make the following assumptions

Assumption 1. $\delta>R .{ }^{19}$

\footnotetext{
${ }^{19}$ Gandhi and Lustig (2013) find that investors require a lower return on equity when they expect "Too-BigTo-Fail" institutions to be bailed out, such that $\delta$ will be approximately the same for sound and vulnerable banks when implicit guarantees are substantial.
} 
Assumption 1 states that the opportunity cost of capital exceeds the return of the illiquid asset in success states. This assumption ensures that the banker's optimization problem has a solution.

Assumption 2. $(1-\bar{\gamma}) R-\left(\bar{\gamma}-\gamma_{L}\right)<r_{d} \leq\left(1-\gamma_{H}\right) R+\left(\bar{\gamma}-\gamma_{L}\right)$.

Assumption 2 has a dual role. It ensures that in isolation banks do not wish to fully insure against the liquidity shock. Also, it provides the necessary conditions for defaults by contagion.

Assumption 3. (a) $C\left(\theta_{L}\right)>(1-\beta)\left\{\left[(1-\bar{\gamma}) R-r_{d}-r_{I B}^{i}\left(G_{1}\right)\right] \phi_{i}\left(G_{1}\right)-2 \nu\right\} .{ }^{20}$

$$
\text { (b) } C\left(\theta_{H}\right)<(1-\beta)\left\{\left[(1-\bar{\gamma}) R-r_{d}-r_{I B}^{i}\left(G_{1}\right)\right] \phi_{i}\left(G_{1}\right)-2 \nu\right\} .^{21}
$$

Assumption 3 ensures heterogeneity in illiquid asset selection based on the exogenously assigned ability.

Assumption 4. $\beta^{\star} \geq \frac{1+\sqrt{13}}{6} .^{22}$

Finally, assumption 4 states that the perceived probability of success is high enough. It provides the necessary conditions for interbank lending.

\section{Equilibrium in the absence of regulation}

In this section, I characterize the equilibrium by analyzing the capital, liquidity, illiquid asset and network connectivity choices in the absence of regulation.

Lemma 1 characterizes the capital choice.

Lemma 1. (Capital choice) Under assumption 1, in any unregulated equilibrium banks choose to hold $k^{\star}=0$.

Proof. The proof is in the appendix.

The result that banks do not wish to hold any capital follows directly from the assumption that the opportunity cost of capital exceeds the return of the illiquid asset in the success states of nature. That is, regardless of the bank illiquid asset's type, an additional unit of capital reduces unambiguously profits. Moreover, since interbank credit lines are priced such that banks with a cash surplus are indifferent between lending and not lending, lenders do not wish to hold capital to withstand the default of a borrower.

\footnotetext{
${ }^{20}\left[(1-\bar{\gamma}) R-r_{d}-r_{I B}^{i}\left(G_{1}\right)\right] \beta \phi_{i}\left(G_{1}\right)+B+2(1-\beta) \nu>\left[(1-\bar{\gamma}) R-r_{d}-r_{I B}^{i}\left(G_{1}\right)\right] \phi_{i}\left(G_{1}\right)+B-C\left(\theta_{L}\right)$. $21\left[(1-\bar{\gamma}) R-r_{d}-r_{I B}^{i}\left(G_{1}\right)\right] \phi_{i}\left(G_{1}\right)+B-C\left(\theta_{H}\right)>\left[(1-\bar{\gamma}) R-r_{d}-r_{I B}^{i}\left(G_{1}\right)\right] \beta \phi_{i}\left(G_{1}\right)+B+2(1-\beta) \nu$.

${ }^{22}$ The full derivation of this assumption is in the appendix.
} 
I turn now to the choice of liquidity. Bankers can either choose to use credit lines to insure against the liquidity shock or hold enough liquidity to cover the negative liquidity shock $\gamma=\gamma_{H}$. The liquidity allocation $y=\gamma_{H}$ involves a risk-return trade-off. This allocation allows banks to survive to the liquidity shock in all states of the world at the cost of a less profitable portfolio. Lemma 2 characterizes the liquidity allocation in isolation

Lemma 2. (Liquidity choice in isolation)Under assumption 1, the liquidity allocation in isolation as a function of $r_{d}$ is as follows

$$
y^{\text {isolation }}\left(r_{d}\right)=\left\{\begin{array}{lll}
\gamma_{H} & \text { if } & 0<r_{d}<\left(1-\gamma_{H}\right) R+\left(\bar{\gamma}-\gamma_{L}\right) \\
\bar{\gamma} & \text { if } & (1-\bar{\gamma}) R-\left(\bar{\gamma}-\gamma_{L}\right)<r_{d} \leq\left(1-\gamma_{H}\right) R+\left(\bar{\gamma}-\gamma_{L}\right) \\
\gamma_{L} & \text { if } & r_{d}>\left(1-\gamma_{H}\right) R+\left(\bar{\gamma}-\gamma_{L}\right)
\end{array}\right.
$$

Proof. The proof is in the appendix.

Assumption 2 ensures that banks choose to hold in isolation the amount of the average shock in liquidity. Furthermore, without aggregate uncertainty, holding $\bar{\gamma}$ units of liquidity is sufficient to ensure the survival of all banks to the liquidity shock provided that the interbank network can redistribute it efficiently. Thus, provided that perceived counterparty risk is low enough, banks will choose $y=\bar{\gamma}$ and use the interbank network to insure against liquidity shocks. This allows them to preserve a more ex ante profitable portfolio without risking failing to re-finance their illiquid asset. This situation amounts to holding the banks' balance sheet constant, but allowing the use of interbank credit lines to insure against the liquidity shocks. Given the liquidity allocation, the size of the interbank credit lines is immediately determined. Note $y=\bar{\gamma}$ implies that each credit line extended by the liquidity surplus bank $j$ to liquidity deficit bank $i$ amounts to $z_{i}^{j \star}(G, \omega)=\gamma_{H}-\bar{\gamma}=\bar{\gamma}-\gamma_{L}$, the remainder needed to cover the adverse liquidity shock $\gamma_{H}$.

In characterizing the equilibrium, I assume that $y^{\star}=\bar{\gamma}$ and then show under which conditions this is the case. I start by analyzing how a fundamental default takes place and then after determining how counterparty risk is priced into these interbank connections I ask whether banks wish to behave as I claim they do. Given that a bank can only be a lender if the liquidity shock at the interim date is less than $\bar{\gamma}$ when $y=\bar{\gamma}$, the return at maturity $(1-\bar{\gamma}) R-\left(\bar{\gamma}-\gamma_{L}\right)$ needs to be greater than $r_{d}$ to ensure solvency. Assumption 2 ensures that this is not the case, which implies that defaults by contagion may occur in equilibrium. This assumption is a sufficient condition for the probability of a default cascade to be positive. That is, if a borrower obtains the liquidity through an intermediary both the 
intermediary and the original lender may default by contagion. ${ }^{23}$

Suppose $y^{\star}=\bar{\gamma}$, assumption 2 and Lemma 1 then imply that in equilibrium,

$$
r_{I B}^{i \star}\left(G, y, k, \beta^{\star}, R, r_{d}\right)=\sum_{j \in G_{i}^{-}} \frac{\phi_{\omega}^{j}}{\phi_{i}(G)} \frac{1-\beta^{\star}}{\beta^{\star}}\left[(1-\bar{\gamma}) R-r_{d}\right]
$$

and

$$
\epsilon_{i}^{\star}\left(G, \omega, y, k, \beta^{\star}, R, r_{d}\right)=\left\{\begin{array}{ll}
\frac{1-\beta^{\star}}{\left(\beta^{\star}\right)^{2}} \sum_{j \in \tilde{\mathcal{I}}}\left[(1-\bar{\gamma}) R-r_{d}\right] & \text { if } i \text { borrows via intermediary } \\
0 & \text { if } i \text { borrows from direct lender }
\end{array} .\right.
$$

When $\beta^{\star}$ is high enough there are positive profits in using intermediation to offset a liquidity shock that exceeds the bank's liquidity holdings, provided that all banks hold $y=\bar{\gamma}$ in equilibrium. That is, banks will choose $y^{\star}=\bar{\gamma}$ and insure idiosyncratic shocks using interbank connections. That is,

Lemma 3. (Liquidity choice) Under assumptions 2-4, in any unregulated equilibrium banks choose to hold $y^{\star}=\bar{\gamma}$, and the liquidity allocation is independent of the interbank network.

Proof. The proof is in the appendix.

Since bankers with a high cost of asset selection exist, defaults may occur in equilibrium. Moreover, since the model allows for intermediation, the default of a borrower may lead to a default cascade - default of its (direct and indirect) interbank counterparties - in the spirit of Allen and Gale (2000).

After $k^{\star}$ and $y^{\star}$ have been determined, all that remains to be chosen by the banker is the quality of the illiquid asset and his interbank connections. Formally, the banker's expected profit given a network $G$ and his ability $\theta^{i}$ when he is choosing optimally is given by

$$
\pi_{i}^{\star}\left(G, \theta^{i}\right)=\max _{s} \mathbb{E}\left[\pi_{i}\left(G, k^{\star}, y^{\star}, \theta^{i}, s\right)\right] .
$$

Given $\pi_{i}^{\star}\left(G, \theta^{i}\right)$ and assumption 3, all that remains to do is characterize the interbank network, which is done in Proposition 1.

\footnotetext{
${ }^{23}$ This is undoubtedly a strong assumption, but the model's qualitative results only require that regulator's costs in case of default are positively related with vulnerable banks' interconnectedness. Even though first round losses may only have a limited impact on the financial stability, as argued by Glasserman and Young (2014) for example, second round effects may include a downward spiral in asset prices (fire-sales) which may compromise financial stability. Since G-SIBs additional capital charges specifically identify interconnectedness as a relevant factor, this assumption follows from the instrument under analysis.
} 
Proposition 1. Suppose assumptions 1-4 hold, then without regulation high (low) ability bankers choose the sound (vulnerable) illiquid asset, $k^{\star}=0, y^{\star}=\bar{\gamma}$ and the complete network, $G_{1}$ depicted in Figure 2, is PWS.

Figure 2: Complete network, $G_{1}$

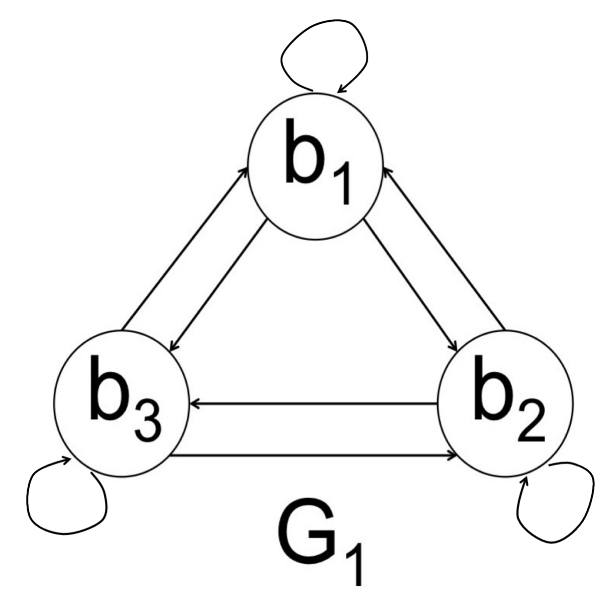

Proof. Note that

$$
\frac{\Delta \pi_{i}^{\star}(\cdot)}{\Delta\left|G^{-}\right|}=\left[(1-\bar{\gamma}) R-r_{d}\right] \frac{\Delta \phi(G)}{\Delta\left|G^{-}\right|}-\frac{\Delta r_{I B}^{i}(G)}{\Delta\left|G^{-}\right|}-\frac{\Delta \epsilon^{\star}(G)}{\Delta\left|G^{-}\right|}>0,
$$

where $\left|G^{-}\right|$is the number of incoming credit lines available to bank $i$.

From assumption 4, it follows that an additional incoming credit line increases expected profit even if it leads a borrower to incur in intermediation fees. Thus, a bank always wishes to establish an additional incoming credit line. Moreover, since the interest rate reflects the implicit guarantees adjusted probability of default, a potential lender is always willing to extend a credit line to another bank.

\section{Regulator's problem}

In the previous section we have seen that the complete network is PWS in the absence of regulation. This implies that in an unregulated equilibrium banks fail to internalize the financial distress costs that are imposed on the regulator. Thus, they may choose to become overly interconnected from a social point of view. In this section, I analyze the conditions under which this is true both when the regulator has complete and incomplete information with respect to banks' tail risk exposure. 
I assume that the regulator maximizes total welfare. Following Giammarino et al. (1993), total welfare is expressed as the sum of the banks' expected profits net of the banker's discretionary resources that are not socially valuable, $\tilde{\pi}(\cdot)$, minus expected financial distress $\operatorname{costs}(\mathbb{E}[\rho(G, \theta, \omega, \tilde{r})])$ augmented by the deadweight loss $(\lambda>0)$ introduced by funding $\rho(G, \theta, \omega, \tilde{r})$ using distortionary taxation (see Freixas; 1999 and Acharya and Yorulmazer; 2007). Financial distress costs, $\rho(G, \theta, \omega, \tilde{r})$, include both deposit insurance costs and the costs associated with the disruption in the financial system brought by default events. These disruption costs are determined by the regulator's choice between a bail out and a bank closure. This is the source of the time-inconsistency problem which motivates the bail out subsidy $\nu$ which accrues to vulnerable banks. Ex ante the regulator would like to commit to close problematic banks, which would eliminate $\nu$ and would potentially induce vulnerable banks to become less interconnected, but ex post she may find it optimal to choose a bail out. If the regulator chooses to bail out a troubled bank, she bears the network-dependent costs of bailing out all stakeholders other than depositors when a default event occurs, which I denote by $\widetilde{\nu}(G, \omega, \tilde{r})$. These costs are increasing in the number of incoming credit lines held by vulnerable banks. Alternatively, she can choose to close down a problematic bank and bear the costs associated with re-stabilizing the financial system, $\eta$ (\# defaults $\mid G, \theta, \omega, \tilde{r})$, which are increasing and (discrete) convex in the number of defaults. Since banks are unsure of what is the ex post choice of the regulator, they formulate an expectation over these bail out subsidies, $\nu$, which ultimately depends on the institutional framework in which both the regulator and the banks operate. Formally,

$\rho(G, \theta, \omega, \tilde{r})=r_{d} \mathbb{E}[\#$ defaults $\mid G, \theta, \omega, \tilde{r}]+\min \{\widetilde{\nu}(G, \omega, \tilde{r}), \eta(\# \operatorname{defaults} \mid G, \theta, \omega, \tilde{r})\}$,

and the welfare function is given by

$$
\mathbb{W}(G, y, \theta, k)=\sum_{i=1}^{3} \pi_{i}^{\star}\left(\theta^{i} ; G, y, k\right)-(1+\lambda) \mathbb{E}[\rho(G, \theta, \omega, \tilde{r})]+3 r_{d}
$$

\subsection{Regulator's problem under complete information}

Financial regulation is required if the interbank network that emerges in the unregulated equilibrium differs from the one a regulator would choose. In this subsection, I determine under which circumstances this occurs assuming that the regulator is able to observe each bank's type.

Naturally, the regulator can be assumed to have the ability to freely allocate liquidity 
across the system after the shock materializes. However, to compare unregulated and regulated equilibria, I model the liquidity reallocation choice as an interbank network. Even though the regulator is still constrained by the distribution of bankers' ability, ${ }^{24}$ under complete information, she can choose $y, k$ and $G$ conditional on banks' types. ${ }^{25}$ In this context, the network is interpreted as the transfers the regulator is willing to make, conditional on bankers' types, after observing the liquidity shortage but before the return shock materializes. Thus, the regulator's problem under complete information is given by

$$
\max _{G, y, k} \mathbb{W}(G, y, k, \theta)
$$

s.t.

$$
\pi_{i}^{\star}\left(\theta^{i} ; G, y, k\right) \geq 0
$$

for all $i \in\left\{b_{1}, b_{2}, b_{3}\right\}$.

Even under complete information the regulator faces a trade-off when deciding to what extent she should allow banks to access the interbank infrastructure. On one hand, a more interconnected interbank network increases banks' profits in the success states of the world, but on the other hand it also leads to defaults by contagion in default states. This trade-off becomes clear when taking discrete differences with respect to the network's connectivity in equation (8)

$$
\frac{\Delta \mathbb{W}(\cdot)}{\Delta|G|}=\sum_{i=1}^{3} \frac{\Delta \tilde{\pi}_{i}(\cdot)}{\Delta|G|}-(1+\lambda) \frac{\Delta \mathbb{E}[\rho(\cdot)]}{\Delta|G|} \gtreqless 0 .
$$

Although equation (9) cannot be signed unambiguously, it is instructive to analyze how this trade-off is affected by changes in other parameters. From this equation, it follows that the net social value of interconnectedness of vulnerable banks is decreasing in the costs of default. Thus, the regulator never allows vulnerable banks to borrow from other banks when these costs are sufficiently high. Formally,

Proposition 2. Let $G^{\prime}$ be a network obtained from $G_{1}$ removing some or all of the vulnerable

\footnotetext{
${ }^{24}$ Alternatively, I could have considered the case where regulation acts directly by replacing vulnerable by sound bankers, or even more drastically withdraw their banking license.

${ }^{25}$ In my model, capital only plays the role of a Pigouvian tax. This can be motivated by the focus on tail risk, that is, in order to create a buffer against low probability high impact events banks would be required to hold a considerable amount of capital that might be unfeasible. Moreover, the regulator may have limited ability to determine the precise buffer that prevents failures when banks misreport their exposures. As argued by Huizinga and Laeven (2012), the evidence that financial reports may provide a distorted picture of banks' resilience can be found in the result of the 2009 US stress tests. These tests revealed capital shortages even though reports gave the appearance that the minimum regulatory requirements were fulfilled.
} 
banks incoming connections. When $\lambda$ is high enough, implicitly defined by

$$
\lambda>\frac{\sum_{i=1}^{3} \widetilde{\pi}_{i}\left(G_{1}, \cdot\right)-\widetilde{\pi}_{i}\left(G^{\prime}, \cdot\right)}{\mathbb{E}\left[\rho\left(G_{1}, \theta\right)\right]-\mathbb{E}\left[\rho\left(G^{\prime}, \theta\right)\right]}-1,
$$

then the welfare allowed by $G^{\prime}$ is higher than the one allowed by $G_{1}$.

Proof. The proof follows directly from equation (9). Denoting $G_{1}^{\prime}$ as any network obtained from $G_{1}$ in which vulnerable banks are, at some extent, denied participation in the interbank market, which reduces expected financial disruption costs, the implicit condition in the Proposition is the following

$$
\begin{aligned}
& \sum_{i=1}^{3} \frac{\Delta \widetilde{\pi}_{i}(\cdot)}{\Delta|G|}-(1+\lambda) \frac{\Delta \mathbb{E}[\rho(\cdot)]}{\Delta|G|}<0 \Leftrightarrow \\
& \Leftrightarrow \lambda>\frac{\sum_{i=1}^{3} \widetilde{\pi}_{i}\left(G_{1}, \cdot\right)-\widetilde{\pi}_{i}\left(G_{1}^{\prime}, \cdot\right)}{\mathbb{E}\left[\rho\left(G_{1}, \theta\right)\right]-\mathbb{E}\left[\rho\left(G_{1}^{\prime}, \theta\right)\right]}-1 .
\end{aligned}
$$

A natural question then is what is the socially optimal network or networks. Since even under complete information the regulator faces a trade-off between efficiency and financial stability, the socially optimal financial network is determined by the factors that affect the steepness of this trade-off.

Lemma 4. As the costs with the disruption of the functioning of the financial system increase, the socially optimal networks are $G_{1}, G_{2}, G_{3} / G_{3}^{\prime}$ and $G_{4}$, respectively. See Figure 3.

Proof. The proof is in the appendix.

There are three candidate networks, depicted in Figure 3. Network $G_{2}$ allows the sound bank to benefit from full liquidity insurance, while vulnerable banks only benefit from partial liquidity insurance. Networks $G_{3}$ and $G_{3}^{\prime}$ allow the sound bank to benefit from full liquidity insurance, while only one vulnerable bank benefits from partial liquidity insurance. Thus, efficiency is partially preserved and contagion is reduced only at the cost of decreasing vulnerable banks' liquidity insurance probability. Finally, in network $G_{4}$ the sound bank still obtains full liquidity insurance, but now vulnerable banks cannot insure against the liquidity shock using the interbank market. Thus, total absence of contagion is gained at the cost of confining vulnerable banks to isolation. 
Figure 3: Socially Optimal Networks
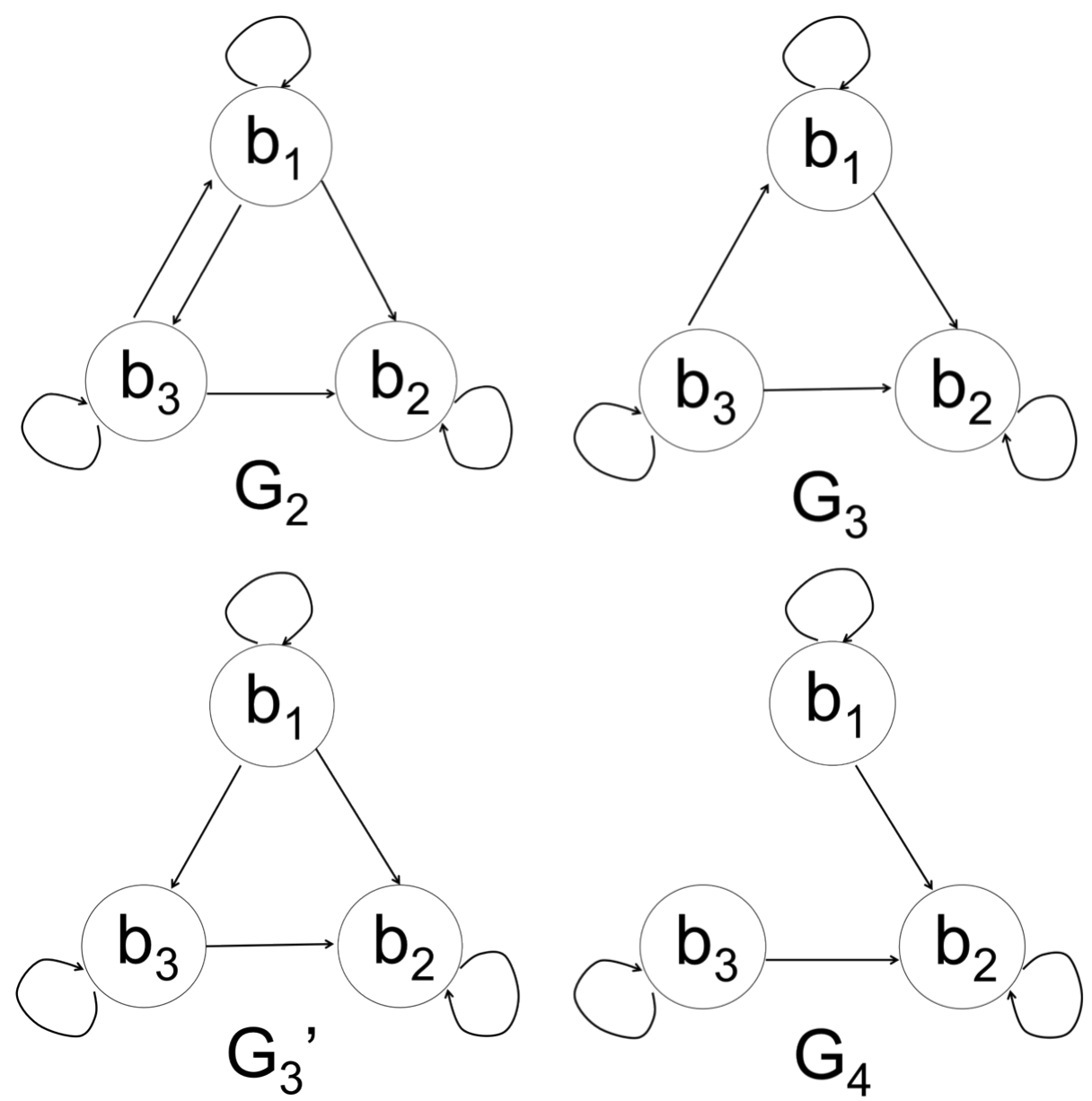

As Lemma 4 shows, when the regulator is able to design the interbank network, she would never use undifferentiated capital requirements since they are not the most effective among all the alternative instruments available. Even though the regulator wishes to limit propagation of distress following a vulnerable bank's default, imposing capital requirements on sound ones unambiguously decreases total welfare. This observation further motivates the assumption that an informational friction may constrain regulatory design and consequently it deserves consideration.

\subsection{Regulator's problem under incomplete information}

In this subsection, I assume that the regulator has incomplete information with respect to banks' tail risk exposure. ${ }^{26}$ Now, the regulator is no longer able to condition the instru-

\footnotetext{
${ }^{26}$ The assumption that the regulator is not able to infer ex ante the ability of each banker from risk exposures can be motivated as follows. First, as previously argued by Blum (2008), very large banks are
} 
ment on banks' types. Thus, this instrument must induce banks to voluntarily reveal their type through their optimal choices. That is, macroprudential regulation must be incentive compatible.

Following the "additional loss absorbency requirement" in broad terms, I assume that the regulator imposes a capital requirement $\kappa$ per incoming credit line. ${ }^{27}$ To accommodate capital requirements, I add a new date, $t=-1 / 2$, to the model where the regulator fixes capital charges. Then, during the network formation stage banks treat the capital charges as an exogenous cost to form credit lines. Under incomplete information, the regulator's problem is now given by

$$
\max _{G, \kappa} \mathbb{W}(G, \theta, \kappa)
$$

s.t.

$$
\begin{aligned}
& \pi_{i}^{\star}\left(G, \theta^{i} ; \kappa\right) \geq 0 \\
& \pi_{i}^{\star}\left(G, \theta^{i} ; \kappa\right) \geq \pi_{i}^{\star}\left(G^{\prime} \theta^{i} ; \kappa\right),
\end{aligned}
$$

$\forall i \in\left\{b_{1}, b_{2}, b_{3}\right\}$.

The first set of constraints in equation (11) is the set of individual rationality constraints (or participation constraints) and the second set in equation (12) comprises the incentive compatibility constraints. ${ }^{28}$ The individual rationality constraints state that under $\kappa$ each bank is better off continuing its operations rather than exiting the market. In this case, the intersection of the second set of constraints has a particular meaning since it expresses that banks will only choose those networks that are pairwise-stable given $\kappa$.

Given that contagion costs come from vulnerable banks' interconnectedness decisions, the regulator would like to limit only vulnerable banks participation in the interbank net-

complex organizations, whose assets are opaque such that even supervisors may be unable to assess perfectly ex ante the exposure to low probability high impact events. Second, banks (especially ones of systemic importance) may choose optimally to misreport their true tail risk exposures (see Huizinga and Laeven; 2012) since not only it makes them subject to higher capital charges but also they may anticipate regulatory forbearance. One potential explanation for this response is the regulator's desire to maintain a strong reputation of a good screener of unsound banks (as argued by Morrison and White; 2013) with the objective of avoiding contagion effects that would undermine the confidence in the stability of the financial system. Finally, also as argued by Blum (2008), if there is no asymmetry of information to begin with, then capital requirements can be replaced with quantitative risk restrictions since bank behavior is perfectly anticipated.

${ }^{27}$ This assumption restricts the contract space to a linear function in interconnectedness. However, there is no reason to expect the optimal contract to be linear. Further investigation of the optimal regulatory contract is left for future research.

${ }^{28}$ As shown by Myerson (1979), this representation is without loss of generality given the revelation principle. 
work. However, unconditional per-connection capital charges also limit sound banks' participation. Since it is not possible to restrict the participation of vulnerable banks in the interbank network without also restricting sound ones', the first best cannot be achieved. Interconnectedness-based requirements generate a trade-off to the banker between raising additional capital and benefitting from increased connectivity. This added cost can affect the interbank network that emerges as the equilibrium outcome. Thus, analyzing capital requirements within a network formation game allows to design an instrument that takes into account how optimizing agents react to it.

From the regulator's standpoint, choosing $\kappa$ involves a series of trade-offs. On one hand, by choosing higher capital requirements based on the number of incoming credit lines the regulator can reduce interconnectedness and thus reduce financial distress costs. On the other hand, reduced interconnectedness achieved through higher capital requirements also reduces liquidity insurance and increases capital costs leading to a decrease in banks' profits. When the regulator adopts a given $\kappa$, she creates an undifferentiated added cost of adding an incoming credit line. However, banks do not benefit equally from increased interconnectedness. The heterogeneity in bankers' ability, that is translated into individual risk-taking, has an immediate implication for the additional value of each connection in the interbank market. Sound banks' profits increase by the full amount allowed by insurance in additional states of the world. However, vulnerable banks only benefit with probability $\beta$ from the return (net of the interbank interest rate) of additional liquidity insurance and with probability $1-\beta$ from the bail out subsidy. These differences can be analyzed in detail by decomposing the incremental profit allowed by each interbank connection both for sound and vulnerable banks. That is,

$$
\frac{\Delta \pi_{i}^{\star}\left(\cdot, \theta_{H} ; \kappa\right)}{\Delta\left|G_{i}^{-}\right|}=\left[(1-\bar{\gamma}) R-r_{d}\right] \Delta \phi_{i}-\Delta r_{I B}^{i} \phi_{i}-\Delta \epsilon_{i}-\left[\delta-R\left(\left|G_{i}^{\prime \prime}-\right| \Delta \phi_{i}+\phi_{i}(G)\right)\right] \kappa,
$$

where $G^{\prime \prime}$ is a network obtained from $G$ by eliminating one incoming credit line to bank $i$. The incremental profit of a sound bank allowed by an additional incoming credit line is increasing in the return of the illiquid asset and in the probability of occurrence of the states characterized by a liquidity shock to which the credit line insures against. Also, it is decreasing in the interest rates and in the opportunity cost of capital. Similarly,

$$
\begin{aligned}
\frac{\Delta \pi_{i}^{\star}\left(\cdot, \theta_{L} ; \kappa\right)}{\Delta\left|G_{i}^{-}\right|}= & {\left[(1-\bar{\gamma}) R-r_{d}\right] \beta \Delta \phi_{i}-\beta \Delta r_{I B}^{i} \phi_{i}-\beta \Delta \epsilon_{i}+(1-\beta) \nu-} \\
& {\left[\delta-R \beta\left(\left|G_{i}^{\prime \prime}-\right| \Delta \phi_{i}+\phi_{i}(G)\right)\right] \kappa . }
\end{aligned}
$$


That is, the incremental profit of a vulnerable bank allowed by an additional incoming credit line is increasing in the return of illiquid asset in success states, in the probability of occurrence of the liquidity shock and in the bailout subsidy $\nu$. Then, it follows from equations (13) and (14) that sound and vulnerable bankers wish to establish an additional credit line if $\kappa$ is low enough, i.e.,

$$
\begin{aligned}
& \frac{\Delta \pi_{i}^{\star}\left(\cdot, \theta_{H} ; \kappa\right)}{\Delta\left|G_{i}^{-}\right|}>0 \Leftrightarrow \\
& \kappa<\left\{\left[(1-\bar{\gamma}) R-r_{d}\right] \Delta \phi_{i}-\Delta r_{I B}^{i} \Delta \phi_{i}-\Delta \epsilon_{i}\right\} /\left[\delta-R\left(\left|G_{i}^{\prime \prime}-\right| \Delta \phi_{i}+\phi_{i}(G)\right)\right] \equiv \kappa_{s}\left(\Delta \phi_{i} ; \delta, R, r_{d}\right),
\end{aligned}
$$

and

$$
\begin{aligned}
& \frac{\Delta \pi_{i}^{\star}\left(\cdot, \theta_{L} ; \kappa\right)}{\Delta\left|G_{i}^{-}\right|}>0 \Leftrightarrow \\
& \kappa<\frac{\left[(1-\bar{\gamma}) R-r_{d}\right] \beta \Delta \phi_{i}-\beta-\Delta r_{I B}^{i} \phi_{i}-\beta \Delta \epsilon_{i}+(1-\beta) \nu}{\delta-R\left(\left|G_{i}^{\prime \prime}\right| \Delta \phi_{i}+\phi_{i}(G)\right)} \equiv \kappa_{v}\left(\Delta \phi_{i} ; \delta, R, r_{d}, \nu\right) .
\end{aligned}
$$

Importantly, since the negative externality arises because vulnerable banks are overly connected from the regulator's point of view, the trade-off between financial stability and efficiency depends on how much sound and vulnerable banks value interbank connections. If sound banks value relatively more credit lines, then it is possible to induce vulnerable banks to reduce their interconnectedness without reducing the benefits of liquidity insurance to sound banks, ceteris paribus. Even in this case there is a trade-off between financial stability and efficiency. By reducing the extent to which vulnerable banks participate in the interbank market, and thus improving stability, efficiency is still reduced because all banks have to raise more capital. However, if vulnerable bankers value relatively more interbank connections, then the trade-off becomes steeper, given that now more efficiency needs to be foregone to improve financial stability. To understand under which conditions each scenario arises, one needs to inspect the difference between equations (13) and (14). That is,

$$
\frac{\Delta \pi_{i}^{\star}\left(\cdot, \theta_{H} ; \kappa\right)}{\Delta\left|G_{i}^{-}\right|}-\frac{\Delta \pi_{i}^{\star}\left(\cdot, \theta_{L} ; \kappa\right)}{\Delta\left|G_{i}^{-}\right|}=(1-\beta)\left\{\left[(1-\bar{\gamma}) R-r_{d}\right] \Delta \phi_{i}-\Delta \epsilon_{i}-\nu+R\left(\left|G_{i}^{\prime \prime}-\right| \Delta \phi_{i}+\phi_{i}(G)\right) \kappa\right\} .
$$

Thus, vulnerable banks value relatively more credit lines if

$$
\Leftrightarrow \kappa<\left\{\nu-\left[(1-\bar{\gamma}) R-r_{d}\right] \Delta \phi_{i}+\Delta \epsilon_{i}\right\} / R\left(\left|G_{i}^{\prime \prime}-\right| \Delta \phi_{i}+\phi_{i}(G)\right) \equiv \bar{\kappa} .
$$

Proposition 3 summarizes these results. 
Proposition 3. If $\kappa_{s}>\bar{\kappa}$ the regulator can induce vulnerable banks to reduce their interconnectedness without affecting the extent to which sound banks benefit from participating in the interbank market.

Proof. The proof follows from equations (12), (13) and (14). The formal proof is in the appendix.

Under incomplete information, the regulator cannot condition $\kappa$ on banks' types. Thus, when $\kappa$ is defined strictly on the number of connections established, the extent to which vulnerable banks participate in the interbank market can only be reduced by choosing $\kappa$ high enough so that they do not wish to increase their interconnectedness. However, if vulnerable banks value relatively more credit lines, which occurs if $\bar{\kappa}>\kappa_{s}$, then it is not possible to induce them to eliminate connections without also inducing sound banks to do the same.

Proposition 3 shows that, under incomplete information, the regulator is constrained in her ability to induce banks to form the socially efficient interbank network. Moreover, this ability is affected by the size of bail out subsidies. In its turn, the relevance of this distortion can be traced back to the particular institutional framework, which I discuss in section 7 .

\section{$7 \quad$ Policy implications}

In this section I present the policy implications of my model.

\subsection{Resolution regimes}

In addition to the higher loss absorbency requirement extensively discussed in this paper, that reduce the probability of default of G-SIBs, the (Financial Stability Board; 2010) developed measures to improve resolution and recovery regimes with the objective of "reduce the extent or impact of failure of G-SIBs" (BCBS; 2011, p. 3). The analysis carried out in this paper suggests that resolution regimes may play an additional role in financial stability. Since effective resolution frameworks reduce ex-post costs of G-SIBs failures, they lend credibility to closure policies. This reduces expected bail out subsidies $\nu$. If these subsidies are related not only with size but also with interconnectedness, then this implies that vulnerable banks, the likely recipients of these subsidies, value less their connections. Consequently, it becomes more effective for an informationally constrained regulator to induce vulnerable banks to become less interconnected using capital requirements. Thus, not only resolution regimes complement capital charges by reducing the impact of G-SIB failures, but also they make capital requirements more effective in correcting the misalignment between private and social incentives when implicit government guarantees are significant. 


\subsection{Bank levies}

Following the proposals made at the G-20 meetings (IMF; 2010), since the beginning of 2011, bank levies were introduced in several European countries ${ }^{29}$ namely France, Germany, Portugal and the United Kingdom. For example, in Germany 'relevant liabilities' under 10 billion EUR are subject to a $0.02 \%$ rate, under 100 billion EUR to $0.03 \%$ and over 100 billion EUR to $0.04 \%$. Since an increase in interconnectedness increases the liabilities base, this type of levy in effect introduces a cost to interconnectedness. Therefore, it is similar to interconnectedness-based capital requirements and the results of the paper also apply to it.

\subsection{Liquidity regulation}

Proposition 3 was derived under the assumption that liquidity and return shocks are independent. However, it may be more reasonable to assume that vulnerable banks face higher than average liquidity shocks with a higher probability than sound ones do (i.e., $\operatorname{prob}\left(\gamma=\gamma_{H} \mid s=\operatorname{vuln}.\right)>\operatorname{prob}\left(\gamma=\gamma_{H} \mid s=\operatorname{sound}\right)$ or $\left.\min \left\{\phi_{2}, \phi_{3}, \phi_{4}, \phi_{5}\right\}>\max \left\{\phi_{1}, \phi_{6}\right\}\right)$. This can be the case if assets with higher exposure to return shocks also need to be refinanced with a higher probability. For example, correlation between return and (funding) liquidity risk can be motivated with reference to a business model where banks fund long-term assets exposed to tail risk with short-term liabilities. Maturity mismatch of this type would lead vulnerable bankers to value comparatively more an additional interbank credit line. Thus, correlation between liquidity and credit risk plays an analogous role to implicit guarantees in constraining the regulator's ability to limit the participation of vulnerable banks in the interbank market. If that is the case, a liquidity requirement such as the Net Stable Funding Ratio (NSFR) brought by Basel III can improve the effectiveness of interconnectedness-based capital requirements. This would correspond to setting a lower bound to $y$ in the context of the model. In its turn, this would make defaults by contagion less likely and consequently reduce expected external costs imposed on the regulator in consequence of a default.

\section{Conclusion}

The 2007-09 subprime crisis triggered a major regulatory reform. In addition to strengthening microprudential standards, the new regulatory framework brought a series of macroprudential instruments that aim to contain systemic risk at socially acceptable levels.

Motivated by contagion concerns, one class of these new instruments targets the connections established among financial institutions. Yet, interconnectedness is in itself an

\footnotetext{
${ }^{29}$ At the time, Sweden had already in place a 'Stability Fee' based on bank's liabilities.
} 
equilibrium outcome and as such is affected by any instrument made contingent on it. In this paper, I analyze a microfounded design of interconnectedness-based capital requirements that not only explicitly accounts for the endogenous response of the regulated institutions, but also accounts for the impact of asymmetric information and implicit government guarantees in the design of the instrument. I show that when the informational friction interacts with implicit government guarantees the regulator faces a steeper efficiency-financial stability trade-off. This is the case not only because more capital is required to induce vulnerable banks to become less interconnected, but also because in this process sound banks' interconnectedness may also be reduced. This finding underscores the importance of complementary measures, such as credible resolution regimes, that mitigate these frictions. Not only improved resolution regimes may reduce directly the impact of G-SIB failures, but also they can make the regulatory trade-off between financial stability and efficiency less burdensome when banks' interconnectedness decisions generate negative externalities. That is, not only interconnectedness-based capital requirements and resolution regimes are complementary, they are also mutually reinforcing.

It is instructive to ask how this result would change when the assumptions of the model are relaxed. First, even though the two extreme cases presented in this paper with respect to the ability of the regulator to observe tail risk exposures ex ante are not realistic, they provide useful benchmarks. A more realistic assumption is the case where the regulator is able to condition capital requirements on some ex ante imperfect signal of risk exposures, such as risk weighted assets as it is the case in the G-SIBs additional loss absorbency requirement. However, provided that the signal is noisy, such that vulnerable assets cannot be perfectly distinguished from sound ones, the main economic argument still holds. That is, the regulator still faces a trade-off between constraining investment in sound assets and limiting the negative externality posed by vulnerable ones. Second, the assumption that the interbank network is perfectly observed by the regulator is undoubtedly a strong assumption. Moreover, it contrasts with the assumption that tail risk exposure is not observed by the regulator at an individual level. Even though interbank exposures may be hard to identify, tail risk exposure may be even harder to measure. The difference may lie on the fact that while connections may already be in place, tail risk may only manifest itself at some unknown point in the future. Finally, throughout the paper, I fixed the ability distribution. However, since all results are established based on the types of banks involved, the assumption regarding a particular distribution is without loss of generality. 


\section{References}

Acharya, V. V. and Yorulmazer, T. (2007). Too many to fail-an analysis of time-inconsistency in bank closure policies, Journal of Financial Intermediation 16(1): 1-31.

Allen, F. and Babus, A. (2009). Networks in finance1, The Network Challenge: Strategy, Profit, and Risk in an Interlinked World p. 367.

Allen, F., Babus, A. and Carletti, E. (2012). Asset commonality, debt maturity and systemic risk, Journal of Financial Economics 104(3): 519-534.

Allen, F. and Gale, D. (2000). Financial contagion, Journal of Political Economy 108(1): 133.

Anand, K., Gai, P. and Marsili, M. (2012). Rollover risk, network structure and systemic financial crises, Journal of Economic Dynamics and Control 36(8): 1088-1100.

Battiston, S., Gatti, D. D., Gallegati, M., Greenwald, B. and Stiglitz, J. E. (2012). Default cascades: When does risk diversification increase stability?, Journal of Financial Stability 8(3): 138-149.

Bayazitova, D. and Shivdasani, A. (2012). Assessing tarp, Review of Financial Studies 25(2): $377-407$.

BCBS (2011). Global systemically important banks: assessment methodology and the additional loss absorbency requirement.

Bluhm, M., Faia, E. and Krahnen, J. P. (2013). Endogenous banks networks, cascades and systemic risk, Technical report, Mimeo, Goethe University.

Bluhm, M. and Krahnen, J. P. (2014). Systemic risk in an interconnected banking system with endogenous asset markets, Journal of Financial Stability .

Blum, J. (2008). Why basel II may need a leverage ratio restriction?, Journal of Banking and Finance 32(8): 1699-1707.

Braun, N. and Gautschi, T. (2006). A nash bargaining model for simple exchange networks, Social Networks 28(1): 1-23.

Caballero, R. J. and Simsek, A. (2013). Fire sales in a model of complexity, Journal of Finance. Forthcoming. 
Campbell, T. S., Chan, Y.-S. and Marino, A. M. (1992). An incentive-based theory of bank regulation, Journal of Financial Intermediation 2(3): 255-276.

Castiglionesi, F. and Navarro, N. (2007). Optimal fragile financial networks, CentER Discussion Paper 2007: 1-39.

Chan, Y.-S., Greenbaum, S. I. and Thakor, A. V. (1992). Is fairly priced deposit insurance possible?, The Journal of Finance 47(1): 227-245.

Cocco, J. F., Gomes, F. J. and Martins, N. C. (2009). Lending relationships in the interbank market, Journal of Financial Intermediation 18(1): 24-48.

Drehmann, M. and Tarashev, N. (2013). Measuring the systemic importance of interconnected banks, Journal of Financial Intermediation. Forthcoming.

URL: $h t t p: / / d x$.doi.org/ 10.1016/j.jfi.2013.08.001

Elliot, M., Golub, B. and Jackson, M. (2014). Financial networks and contagion, The American economic review pp. 3115-3153.

Farboodi, M. (2014). Intermediation and voluntary exposure to counterparty risk, Technical report, Working Paper, University of Chicago.

Financial Stability Board (2010). Reducing the moral hazard posed by systemically important financial institutions: interim report to G20 leaders.

Financial Stability Board (2014). 2014 update of group of global systemically important banks (g-sibs).

Freixas, X. (1999). Optimal bail out policy, conditionality and constructive ambiguity, Discussion paper No. 23\%. LSE Financial Markets Group.

Gai, P., Haldane, A. and Kapadia, S. (2011). Complexity, concentration and contagion, Journal of Monetary Economics 58(5): 453-470.

Gai, P. and Kapadia, S. (2010). Contagion in financial networks, Proceedings of the Royal Society A: Mathematical, Physical and Engineering Science 466(2120): 2401-2423.

Gandhi, P. and Lustig, H. (2013). Size anomalies in us bank stock returns, The Journal of Finance.

Georg, C.-P. (2013). The effect of the interbank network structure on contagion and common shocks, Journal of Banking $\&$ Finance . 
Giammarino, R. M., Lewis, T. R. and Sappington, D. E. (1993). An incentive approach to banking regulation, The Journal of Finance 48(4): 1523-1542.

Glasserman, P. and Young, H. P. (2014). How likely is contagion in financial networks?, Journal of Banking \& Finance .

Griffin, J. M. and Tang, D. Y. (2012). Did subjectivity play a role in cdo credit ratings?, The Journal of Finance 67(4): 1293-1328.

Huizinga, H. and Laeven, L. (2012). Bank valuation and accounting discretion during a financial crisis, Journal of Financial Economics .

IMF (2010). A fair and substantial contribution by the financial sector: April meeting of g-20 ministers, Technical report, International monetary fund (IMF).

Jackson, M. O. and Wolinsky, A. (1996). A strategic model of social and economic networks, Journal of Economic Theory 71(1): 44-74.

Ladley, D. (2013). Contagion and risk-sharing on the inter-bank market, Journal of Economic Dynamics and Control.

Leitner, Y. (2005). Financial networks: Contagion, commitment, and private sector bailouts, The Journal of Finance 60(6): 2925-2953.

Memmel, C. and Sachs, A. (2013). Contagion in the interbank market and its determinants, Journal of Financial Stability 9(1): 46-54.

Morrison, A. D. and White, L. (2005). Crises and capital requirements in banking, American Economic Review pp. 1548-1572.

Morrison, A. D. and White, L. (2013). Reputational contagion and optimal regulatory forbearance, Journal of Financial Economics (forthcoming) .

Mutuswami, S. and Winter, E. (2002). Subscription mechanisms for network formation, Journal of Economic Theory 106(2): 242-264.

Myerson, R. B. (1979). Incentive compatibility and the bargaining problem, Econometrica: Journal of the Econometric Society pp. 61-73.

Senior Supervisors Group (2008). Observation on risk management practices during the recent market turbulence.

Shapley, L. (1950). A value for n-person games, Contributions to the theory of games 2: 307. 
Staum, J. (2012). Systemic risk components and deposit insurance premia, Quantitative Finance 12(4): 651-662.

Tarashev, N., Borio, C. and Tsatsaronis, K. (2009). The systemic importance of financial institutions, BIS Quarterly Review 75: 87.

Upper, C. (2011). Simulation methods to assess the danger of contagion in interbank markets, Journal of Financial Stability 7(3): 111-125.

VanHoose, D. (2007). Theories of bank behavior under capital regulation, Journal of Banking E Finance 31(12): 3680-3697.

Vollmer, U. and Wiese, H. (2013). Minimum capital requirements, bank supervision and special resolution schemes. consequences for bank risk-taking, Journal of Financial Stability $\mathbf{9}(4): 487-497$.

URL: http://www.sciencedirect.com/science/article/pii/S1572308913000533

Zawadowski, A. (2013). Entangled financial systems, Review of Financial Studies 26(5): 1291-1323.

\section{Appendix}

\section{A.1. Details of the interconnectedness criteria of "higher loss ab- sorbency requirements" (excerpt from the rules text p. 7)}

Intra-financial system assets

This is calculated as the sum of:

- lending to financial institutions (including undrawn committed lines);

- holdings of securities issued by other financial institutions;

- net mark to market reverse repurchase agreements;

- net mark to market securities lending to financial institutions; and

- net mark to market OTC derivatives with financial institutions.

Intra-financial system liabilities

This is calculated as the sum of: 
- deposits by financial institutions (including undrawn committed lines);

- securities issued by the bank that are owned by other financial institutions;

- net mark to market repurchase agreements;

- net mark to market securities borrowing from financial institutions; and

- net mark to market OTC derivatives with financial institutions.

The scores for the two indicators in this category are calculated as the amounts of their intra-financial system assets (liabilities) divided by the sum total intra-financial system assets (liabilities) of all banks in the sample.

\section{A.2. Derivation of the main assumptions}

\section{A.2.1. Derivation of the interbank interest rate}

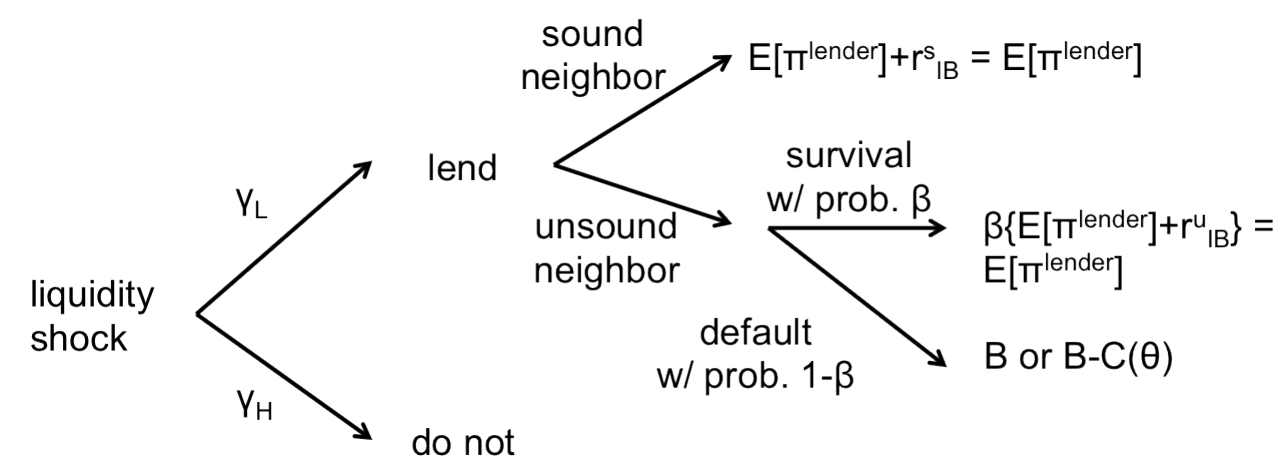

Thus, $r_{I B}^{i, j}=\frac{1-\beta^{\star}}{\beta^{\star}} \mathbb{E}\left[\pi^{\text {lender }}\right]$, where $\pi^{\text {lender }}$ are the lenders' profits on survival stages (or the opportunity cost of defaulting by contagion).

\section{A.2. Proofs}

\section{A.2.1. Proof of Lemma 1}

Note that from the first order conditions

$$
\frac{\partial \mathbb{E}[\pi(\cdot)]}{\partial k}=\left\{\begin{array}{ll}
R \phi(G)-\delta & \text { if } s=\text { sound } \\
R \phi(G) \beta-\delta & \text { if } s=\text { vulnerable }
\end{array} .\right.
$$


it follows that $\frac{\partial \mathbb{E}[\pi(\cdot)]}{\partial k}<0$ regardless the type of illiquid asset chosen when $\delta>R$. Thus, without regulation, banks do not wish to hold any positive amount of capital in their balance sheets.

\section{A.2.2. Proof of Lemma 2}

- expected profit in isolation of $y=\gamma_{L}$

$$
\left[\left(1-\gamma_{L}\right) R-r_{d}\right] \frac{1}{3}
$$

- expected profit in isolation of $y=\bar{\gamma}$

$$
\left[(1-\bar{\gamma}) R-r_{d}\right] \frac{2}{3}+\frac{1}{3}\left(\bar{\gamma}-\gamma_{L}\right)
$$

- expected profit in isolation of $y=\gamma_{H}$

$$
\left(1-\gamma_{H}\right) R-r_{d}+\frac{1}{3}\left(\gamma_{H}-\gamma_{L}\right)+\frac{1}{3}\left(\gamma_{H}-\bar{\gamma}\right)
$$

Under Lemma 1, given assumption 2 and comparing all equations above, it can be shown that

$$
y^{\text {isolation }}=\left\{\begin{array}{lll}
\gamma_{H} & \text { if } & r_{d}<(1-\bar{\gamma}) R-\left(\bar{\gamma}-\gamma_{L}\right) \\
\bar{\gamma} & \text { if } \quad(1-\bar{\gamma}) R-\left(\bar{\gamma}-\gamma_{L}\right)<r_{d} \leq\left(1-\gamma_{H}\right) R+\left(\bar{\gamma}-\gamma_{L}\right) \\
\gamma_{L} & \text { if } & r_{d}>\left(1-\gamma_{H}\right) R+\left(\bar{\gamma}-\gamma_{L}\right)
\end{array}\right.
$$

\section{A.2.3. Proof of Lemma 3}

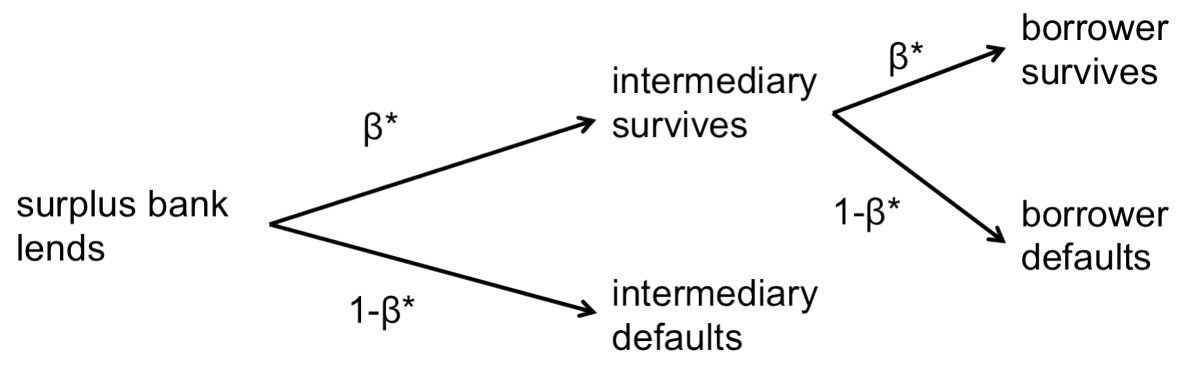

If there are 2 subsequent banks on the intermediation path, the $\epsilon$ that makes the original lender indifferent between lending and not lending is

$$
\beta^{\star 2}\left[\epsilon+(1-y) R-r_{d}\right]=(1-y) R-r_{d} \Leftrightarrow \epsilon=\frac{1-\beta^{\star 2}}{\beta^{\star 2}}\left[(1-y) R-r_{d}\right] .
$$


Similarly when there is only 1 subsequent bank, the $\epsilon$ that makes the original lender indifferent between lending and not lending is

$\beta^{\star}\left[\epsilon+(1-y) R-r_{d}\right]=(1-y) R-r_{d} \Leftrightarrow \epsilon=\frac{1-\beta^{\star}}{\beta^{\star}}\left[(1-y) R-r_{d}\right]$.

Finally, a bank wishes to establish an intermediation relation if after the intermediation fees and interest rate on the interbank loan are paid its profit is still non negative. That is are the ones that

$$
\left[(1-y) R-r_{d}\right]\left(1-\frac{1-\beta^{\star}}{\beta^{\star}}-\frac{1-\beta^{2}}{\beta^{2}}\right) \geq 0 \Leftrightarrow \beta^{\star} \geq \frac{1+\sqrt{13}}{6} .
$$

Note that in this derivation $k$ is set to 0 and $y$ is the same for all banks. Since capital is costly, setting $k=0$ yields the sufficient condition for intermediation to be beneficial for borrower.

\section{A.2.4. Proof of Lemma 4}

The proof follows from the comparison of the welfare levels associated with the different networks. Note that

$$
\begin{aligned}
& \mathbb{W}\left(G_{1}\right)=\left[(1-\bar{\gamma}) R-r_{d}-r_{I B}\right]\left[2\left(\frac{8}{3} \beta-\frac{2}{3} \beta^{2}-1\right)+\frac{1}{3}+\frac{2}{3} \beta\right]- \\
&(1+\lambda)\left\{r_{d}\left(4-\frac{14}{3} \beta+\frac{2}{3} \beta^{2}\right)+\min \left\{\tilde{\nu}\left(G_{1}\right),\left(\frac{8}{3}-4 \beta+\frac{4}{3} \beta^{2}\right) \eta(2)+\frac{2}{3}(1-\beta) \beta \eta(1)\right\}\right\} . \\
& \mathbb{W}\left(G_{2}\right)=\frac{5}{3}\left[(1-\bar{\gamma}) R-r_{d}-r_{I B}\right] 2 \beta-(1+\lambda)\left\{r_{d}\left(4-6 \beta+2 \beta^{2}\right)+\right. \\
&\left.\min \left\{\tilde{\nu}\left(G_{2}\right),\left(2-\frac{10}{3} \beta+\frac{4}{3} \beta^{2}\right) \eta(2)+\frac{2}{3}(1-\beta) \beta \eta(1)\right\}\right\} .
\end{aligned}
$$

$\mathbb{W}\left(G_{4}\right)=\frac{4}{3}\left[(1-\bar{\gamma}) R-r_{d}-r_{I B}\right]\left(\beta^{2}+1\right)+\min \left\{\tilde{\nu}\left(G_{4}\right),(1-\beta)^{2} \eta(2)+2(1-\beta) \beta \eta(1)\right\}$

For $\eta(2)$ large enough and/or $\tilde{\nu}\left(G_{1}\right)>\tilde{\nu}\left(G_{2}\right)=\tilde{\nu}\left(G_{3}\right)>\tilde{\nu}\left(G_{4}\right)$, it follows that $\mathbb{W}\left(G_{4}\right)>$ $\mathbb{W}\left(G_{2}\right)=\mathbb{W}\left(G_{3}\right)>\mathbb{W}\left(G_{1}\right)$.

\section{A.2.5. Proof of Proposition 3}

Note that the incremental profit allowed by an additional incoming credit line for a sound bank is given by 


$$
\begin{aligned}
\frac{\Delta \pi_{i}^{\star}\left(\cdot, \theta_{H} ; \kappa\right)}{\Delta\left|G_{i}^{-}\right|}= & {\left[\left(1+\left(\left|G_{i}^{\prime \prime}-\right|+1\right) \kappa-\bar{\gamma}\right) R-r_{d}-r_{I B}^{i}(G)\right] \phi_{i}(G)-\epsilon_{i}(G)-\delta\left(\left|G_{i}^{\prime \prime}-\right|+1\right) \kappa+} \\
& B-C\left(\theta^{i}\right)-\left[\left(1+\left|G_{i}^{\prime \prime}-\right| \kappa-\bar{\gamma}\right) R-r_{d}-r_{I B}^{i}\left(G^{\prime \prime}\right)\right] \phi_{i}\left(G^{\prime}\right)+\epsilon_{i}\left(G^{\prime \prime}\right)+ \\
& \delta\left|G_{i}^{\prime \prime}-\right| \kappa-B+C\left(\theta^{i}\right)= \\
= & {\left[(1-\bar{\gamma}) R-r_{d}\right] \Delta \phi_{i}-\Delta r_{I B}^{i} \Delta \phi_{i}-\Delta \epsilon_{i}-\left[\delta-R\left(\left|G_{i}^{\prime \prime}-\right| \Delta \phi_{i}+\phi_{i}(G)\right)\right] \kappa, }
\end{aligned}
$$

Similarly, the incremental profit allowed by an additional incoming credit line for a vulnerable bank is given by

$$
\begin{aligned}
\frac{\Delta \pi_{i}^{\star}\left(\cdot, \theta_{L} ; \kappa\right)}{\Delta\left|G_{i}^{-}\right|}= & {\left[\left(1+\left(\left|G_{i}^{\prime \prime}-\right|+1\right) \kappa-\bar{\gamma}\right) R-r_{d}-r_{I B}^{i}(G)\right] \beta \phi_{i}(G)-} \\
& \beta \epsilon_{i}(G)-\delta\left(\left|G_{i}^{\prime \prime}-\right|+1\right) \kappa+B+\nu(1-\beta)\left(\left|G_{i}^{\prime \prime}-\right|+1\right)- \\
& {\left[\left(1+\left(\left|G_{i}^{\prime \prime}-\right|+1\right) \kappa-\bar{\gamma}\right) R-r_{d}-r_{I B}^{i}(G)\right] \beta \phi_{i}\left(G^{\prime \prime}\right)+} \\
& \beta \epsilon_{i}\left(G^{\prime \prime}\right)+\delta\left|G_{i}^{\prime \prime}-\right| \kappa-B-(1-\beta) \nu\left|G_{i}^{\prime \prime}-\right|= \\
= & {\left[(1-\bar{\gamma}) R-r_{d}\right] \beta \Delta \phi_{i}-\beta \Delta r_{I B}^{i} \Delta \phi_{i}-\beta \Delta \epsilon_{i}+(1-\beta) \nu-} \\
& {\left[\delta-R \beta\left(\left|G_{i}^{\prime \prime}-\right| \Delta \phi_{i}+\phi_{i}(G)\right)\right] \kappa . }
\end{aligned}
$$

Therefore, there is a threshold level of per-connection capital requirement above which sound banks do not wish to establish an additional interbank credit line, or alternatively eliminate an existing one, which is given by

$$
\begin{aligned}
& \frac{\Delta \pi_{i}^{\star}\left(\cdot, \theta_{H} ; \kappa\right)}{\Delta\left|G_{i}^{-}\right|}>0 \Leftrightarrow\left[(1-\bar{\gamma}) R-r_{d}\right] \Delta \phi_{i}-\Delta r_{I B}^{i} \Delta \phi_{i}-\Delta \epsilon_{i}-\left[\delta-R\left(\left|G_{i}^{\prime \prime}-\right| \Delta \phi_{i}+\phi_{i}(G)\right)\right] \kappa>0 \Leftrightarrow \\
& \Leftrightarrow \kappa<\left\{\left[(1-\bar{\gamma}) R-r_{d}\right] \Delta \phi_{i}-\Delta r_{I B}^{i} \Delta \phi_{i}-\Delta \epsilon_{i}\right\} /\left[\delta-R\left(\left|G_{i}^{\prime \prime}-\right| \Delta \phi_{i}+\phi_{i}(G)\right)\right] \equiv \kappa_{s}\left(\Delta \phi_{i} ; \delta, R, r_{d}\right),
\end{aligned}
$$

Similar, there is an analogous threshold for vulnerable banks, which is given by

$$
\begin{gathered}
\frac{\Delta \pi_{i}^{\star}\left(\cdot, \theta_{L} ; \kappa\right)}{\Delta\left|G_{i}^{-}\right|}>0 \Leftrightarrow \\
{\left[(1-\bar{\gamma}) R-r_{d}\right] \beta \Delta \phi_{i}-\Delta r_{I B}^{i} \beta \Delta \phi_{i}+\beta \Delta \epsilon_{i}+(1-\beta) \nu-\left[\delta-R \beta\left(\left|G_{i}^{\prime \prime}-\right| \Delta \phi_{i}+\phi_{i}(G)\right)\right] \kappa>0 \Leftrightarrow}
\end{gathered}
$$




$$
\kappa<\frac{\left[(1-\bar{\gamma}) R-r_{d}\right] \beta \Delta \phi_{i}-\beta-\Delta r_{I B}^{i} \Delta \phi_{i}-\beta \Delta \epsilon_{i}+(1-\beta) \nu}{\delta-R\left(\left|G_{i}^{\prime \prime}-\right| \Delta \phi_{i}+\phi_{i}(G)\right)} \equiv \kappa_{v}\left(\Delta \phi_{i} ; \delta, R, r_{d}, \nu\right)
$$

Comparing these two thresholds, yields

$$
\begin{aligned}
& (1-\beta)\left\{\left[(1-\bar{\gamma}) R-r_{d}\right] \Delta \phi_{i}-\Delta \epsilon_{i}-\nu+R\left(\left|G_{i}^{\prime \prime}-\right| \Delta \phi_{i}+\phi_{i}(G)\right) \kappa\right\}<0 \Leftrightarrow \\
& \Leftrightarrow \kappa<\left\{\nu-\left[(1-\bar{\gamma}) R-r_{d}\right] \Delta \phi_{i}+\Delta \epsilon_{i}\right\} / R\left(\left|G_{i}^{\prime \prime}-\right| \Delta \phi_{i}+\phi_{i}(G)\right) \equiv \bar{\kappa} .
\end{aligned}
$$

